\title{
Taking into Consideration the Inclusion of Wind Generation in Hybrid Microgrids: A Methodology and a Case Study
}

\author{
Luis Arribas $^{1, * \mathbb{C}}$, Natalia Bitenc ${ }^{2}$ and Andreo Benech ${ }^{3}$ \\ 1 Renewable Energy Division, CIEMAT, 28040 Madrid, Spain \\ 2 Engineering Department, Higher Technical School of Engineering and Industrial Design, Polytechnic \\ University of Madrid (UPM), 28012 Madrid, Spain; natalia.bitenc@alumnos.upm.es \\ 3 Autonomous Generation Department, National Administration of Power Plants and Electric \\ Transmissions (UTE), Montevideo 2431, Uruguay; abenech@ute.com.uy \\ * Correspondence: lm.arribas@ciemat.es
}

Citation: Arribas, L.; Bitenc, N.;

Benech, A. Taking into Consideration the Inclusion of Wind Generation in Hybrid Microgrids: A Methodology and a Case Study. Energies 2021, 14, 4082. https://doi.org/10.3390/ en14144082

Academic Editors: Adrian Ilinca and Mohamed Benbouzid

Received: 29 April 2021

Accepted: 2 July 2021

Published: 6 July 2021

Publisher's Note: MDPI stays neutral with regard to jurisdictional claims in published maps and institutional affiliations.

Copyright: (c) 2021 by the authors. Licensee MDPI, Basel, Switzerland. This article is an open access article distributed under the terms and conditions of the Creative Commons Attribution (CC BY) license (https:// creativecommons.org/licenses/by/ $4.0 /)$.
Abstract: During the last decades, there has been great interest in the research community with respect to PV-Wind systems but figures show that, in practice, only PV-Diesel Power Systems (PVDPS) are being implemented. There are some barriers for the inclusion of wind generation in hybrid microgrids and some of them are economic barriers while others are technical barriers. This paper is focused on some of the identified technical barriers and presents a methodology to facilitate the inclusion of wind generation system in the design process in an affordable manner. An example of the application of this methodology and its results is shown through a case study. The case study is an existing PVDPS where there is an interest to incorporate wind generation in order to cope with a foreseen increase in the demand.

Keywords: design methodology; WDPS; microgrid; small wind turbine; wind data sources; HOMER Pro

\section{Introduction}

Supplying remote isolated installations with diesel generators into a Diesel Power System (DPS) has traditionally been one of the most common solutions for all sizes of systems, but mainly for low (kWs range) and medium (up to MWs) power ones. With the development of renewable energies, their incorporation into the existing diesel grids started with wind energy due to its lower generation cost in comparison with solar PV, constituting the so called Wind Diesel Power Systems (WDPS) [1]. However, the twenty first century brought a strong reduction in the generation costs for solar PV, which has opened the door to its presence in existing DPS and constitutes the solar PV Diesel Power Systems (PVDPS). Actual trends transitioning to very high percentages of renewable energies (RE) at all levels of power systems induces the need of the Renewable Energy Diesel Power Systems (REDPS), where wind and solar PV technologies might seem to be the most upfront ones and where the presence of medium and long term (usually electrochemical) storage is common in order to reduce the use of fuel consumption.

In recent years, research has shown a growing interest in the use of hybrid wind photovoltaic (PV) systems. Over the past twenty-five years, hundreds of articles have addressed the topic of hybrid systems considering different configurations and final uses (a good representation of these papers can be found in the impressive literature review of photovoltaic-wind hybrid renewable system research by considering the most relevant 550 articles [2]) and, over the past decades, many reviews have made a comprehensive summary of various results obtained, which include, for example, the impressive review on more than 150 recent articles (including review and research articles) on sizing methodologies of hybrid renewable energy systems [3].

On the other hand, REDPS market (which somehow may be associated with Hybrid Systems and Microgrids ones) is well established and has grown during the last years. 
However, the microgrids installed in the last five years have tended to incorporate PV and battery storage with diesel generators as backup (i.e., PVDPS or solar hybrid microgrids), coping with around $63 \%$ of existing microgrids [4]. On the other hand, small scale wind is much less common for microgrids although some combine with diesel or solar PV [5]. Thus, the common approach has become the following: "Solar hybrid microgrids are currently the most viable and reliable solution for off-grid areas with sufficient population and load density" [6].

These figures from the real world REDPS installations are in contrast with the previous figures from the research world, where there is a maintained interest in REDPS publications. This fact evidences a gap between research and the implementation of REDPS, showing that existing research in hybrid PV/wind microgrids consists primarily of feasibility studies, focusing solely on techno-economic aspects of PV/wind solutions [7], however, this is not sufficient for the implementation of such solutions in real applications. The reason for this might be relative to wind technology, however, nowadays wind technology is highly technically and economically developed at the large scale where large companies and consultancies are available for any design because the large size permits the necessary (not small) budget for the design process. The gap comes neither from the design methodology for PV/Wind solutions as there are plenty of examples of different design methodologies available in the literature, nor from the wind technology itself where implementation is widely spread at the large scale.

The following question arises: why is wind generation nearly missing in the microgrid scale? The immediate answer would be that the dramatic cost reduction in the PV generation has taken it out of the playing field, but a pragmatic economic analysis shows that this is not always the case (that is, what the large number of related publications show). There must be other factors hindering the use of wind generation for this scale derived from the small size of the wind technology: Neither the technology nor the economic competitiveness are well achieved and the updated knowledge of this sector is not easy to maintain due to its constant impermanence. The impression coming from experience is that, in many cases, the small wind option is not even considered during the design process because of the lack and relative complexity of updated knowledge with respect to the technology ("implementation of the wind solution was discarded because the data analysis revealed a low energy production of the existing turbines ...; the reason this is not working should be investigated" [8]), the wind resource ("Wind power is intermittent and its generation curve does not match the daytime load profile of communities" [4]), and its costs and main features ("A reduction in the cost of small-scale wind turbines at the same level as that seen with solar is not expected" [4]).

The main barriers identified in [7] for hybrid PV/wind microgrids in Kenya, which could easily be extended to most places in the world, are shown in Table 1, with some comments that will begin to show the scope of this work.

This publication is expected to provide some updated knowledge in order to facilitate the consideration of the inclusion of wind technology in the design of new or repowered REDPS of low power, which is not usually carried out by large consultancies and in which the budget for the design is usually limited by the size of the system.

Table 1. Categorization of the most commonly mentioned barriers for hybrid microgrids (source: Barriers and Explanations from [7]; comments are personal elaboration).

\begin{tabular}{ccc}
\hline Barrier & Explanation & Comment \\
\hline Wind resource quality & $\begin{array}{c}\text { Wind resource is perceived to be } \\
\text { insufficient. }\end{array}$ & $\begin{array}{c}\text { See Section 2.1.3 (a), Sections 2.1.4, 3.1 } \\
\text { and 3.3. }\end{array}$ \\
\hline Technological knowledge & $\begin{array}{c}\text { Knowledge of wind technology and } \\
\text { capacity for development is low. }\end{array}$ & See Section 2.1.3 (b) and Section 3.3. \\
\hline
\end{tabular}


Table 1. Cont.

\begin{tabular}{ccc}
\hline Barrier & Explanation & Comment \\
\hline Governance and regulation & $\begin{array}{c}\text { Lack of framework for implementation of } \\
\text { wind power. Additional regulatory } \\
\text { requirements for wind projects. }\end{array}$ & $\begin{array}{c}\text { Yes, it is misunderstood. That is why } \\
\text { benefits must be clearly understood. }\end{array}$ \\
\hline Cost of wind projects & $\begin{array}{c}\text { The cost of wind power is perceived to be } \\
\text { higher than PV. }\end{array}$ & It may reduce the system LCOE. \\
Community acceptance & $\begin{array}{c}\text { Understanding and acceptance of wind } \\
\text { technology varies. Issues related to noise, } \\
\text { bird incidents, and sickness as a result of } \\
\text { turbines. }\end{array}$ & $\begin{array}{c}\text { In general, these issues are much more } \\
\text { critical in large scale wind: Information } \\
\text { campaigns might help. }\end{array}$ \\
\hline Complexity wind projects & $\begin{array}{c}\text { Wind projects are seen as more complex. } \\
\text { Necessary data are not available. }\end{array}$ & $\begin{array}{c}\text { See Section 2.1.3 (a) and (c), Sections 2.1.4, } \\
\text { and 3.3. }\end{array}$ \\
\hline Suitable technology & $\begin{array}{c}\text { No suitable wind turbine exists. } \\
\text { Low presence of local distributors or } \\
\text { manufacturers. }\end{array}$ & See Section 2.2.1 (b). \\
\hline
\end{tabular}

\section{Materials and Methods}

A methodology to cope with some of the barriers that designers might face when considering small wind turbines as an option during the design process is proposed in this section.

A case study in the form of a feasibility study will then be presented as an example of the application of the proposed. The bulk of this example is not the techno-economic analysis of PV/wind solutions itself but the methods to cope with small wind technology issues within a more or less standard design procedure.

\subsection{Methods: Methodology to Account for Small Wind Turbines Barriers during the Design Process}

The reference design process will be briefly described (Section 2.1.2) once the configuration of the REDPS to be studied has been selected and justified (Section 2.1.1). Then, the main differences arising from the presence of wind generation in REDPS will be identified and the possible existing solutions for each identified factor will be analyzed (Section 2.1.3). Finally, the proposed methodology to account for small wind turbines barriers during the design process will be presented (Section 2.1.4).

\subsubsection{Selection of the Configuration of REDPS to Be Designed}

It is important to select the system configuration at the beginning because different configurations results in different design procedures and, thus, different considerations. The common feature of all the systems covered in this work is the presence of diesel generation. However, REDPS existing today can be classified from a technical point of view into diesel-dominated and inverter-dominated hybrid systems [9] depending on which component is in charge of maintaining grid stability.

- Diesel dominated hybrid systems.

Diesel engines have traditionally been one of the main options when electrifying rural and remote areas. However, the important drawbacks of this option (such as the rising cost of diesel fuel and carbon emissions concerns) when compared to renewable energy opens the door to the inclusion of such renewable energies in diesel dominated grids.

In these systems, the grid is formed by diesel generator(s). In fact, the common case is that there is an already existing grid supplied by the diesel engine(s) to which a renewable energy generating system is connected for retrofitting. Larger systems usually contain more and larger equipment that allows for an economy of scale and thus lowers power costs. 
The system design is strongly related to the amount of energy that is expected from the renewable sources (system penetration), which will define the methods used to control the power system. System penetration can be defined either as Instantaneous penetration (renewable power output divided by the load power) or as Average penetration (renewable energy output divided by the total load energy over a given time period, typically a month or year). Instantaneous penetration relates to the power system complexity to maintain acceptable power quality. Average penetration relates to the steady state general system operation characteristics.

- Inverter dominated hybrid systems.

Most of the existing REDPS systems can be included in this group, which is characterized mainly by the inverters as the grid forming unit, and the use of long-term storage (in the past, usually lead acid batteries) as the main source to stabilize the grid. Fossil fuel generators are present but function as a back-up unit and usually with the options of supplying the load directly and bypassing the inverter if needed. From a configuration point of view, size is not such a great issue for this configuration but it is a fact that size is a very important issue for component availability, cost, and design.

The target configuration for this paper will be the inverter dominated REDPS, with one main diesel generator (there may be two for back up, but only one working at the same time) and with long term (several hours at least) electrochemical storage that is either AC or DC coupling.

\subsubsection{Description of the Design Process}

It may be worth remembering at this point that the methodology presented in this publication is not a design methodology, for which many other proposals have been published [3], but a methodology to cope with small wind turbine barriers during the design process. However, as this methodology is applied together with a design process, it will be briefly presented here.

From a design point of view, PV-Wind REDPS can be roughly considered as PVDPS where wind generation is added, as depicted in Figure 1. This approach has the advantage of allowing the use of all knowledge coming from existing solar PV standalone systems, which is quite extentsive.

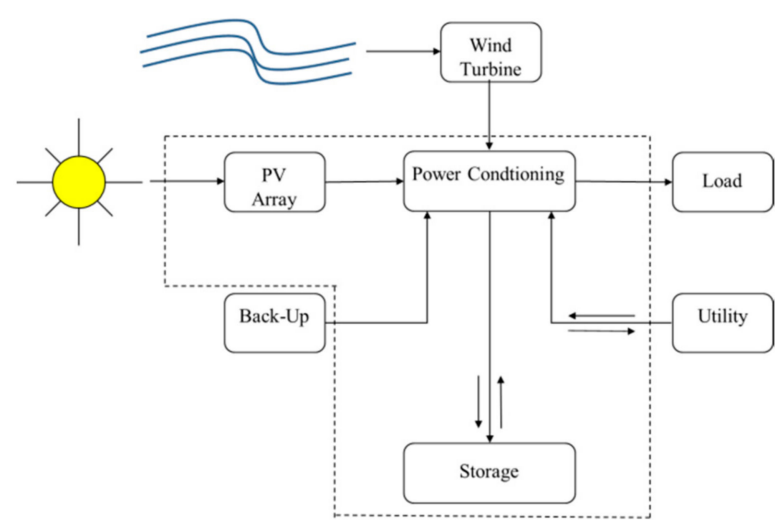

Figure 1. From a basic point of view, the design of Wind-PV-Diesel Power Systems may be seen as PVDPS where wind generation is added (adapted from [10]).

The research in REDPS might have started at the time when the IEA's Task 8 (19851994) "Study of Decentralized Applications for Wind Energy" aimed both to define costeffective models and techniques suitable for obtaining wind and load data necessary for planning and specifying decentralized wind energy conversion installations and to apply and further develop models suitable for analyzing the performance of wind-diesel systems. The results of this collaborative research were summarized in the book "Wind-Diesel Systems", published by the Cambridge University Press [11]. At that time, the inclusion of 
solar PV generation was so expensive that it was not even considered. Since then, some implementation guidelines have already been proposed for both PV-Hybrid Systems [12] and Wind Hybrid systems $[13,14]$, which both have many elements in common with PVWind Hybrid systems or even for small wind turbines (SWT) [15]. Some call for tenders for REDPS and offer their own design methodology [5].

From these guidelines, an adaptation has been made to update those particular issues that arise in PV-Wind DPS systems in three design stages: data collection, sizing study, and implementation Project.

\subsubsection{Differences Arising from the Presence of Wind Generation in PV-Wind REDPS}

It is a fact that the inclusion of wind generation results in different uncertainties in the design process of the system which needs to be taken into account. Some of the most important ones are addressed in the following paragraphs.

\section{(a) Characterization of Wind Resource}

Firstly, wind resource is much more variable (both temporarily and spatially) than solar resource and there is no geometrical method to predict it (in the case of solar resource, calculations of solar-Earth geometry provide a good estimation from latitude). This means that, on one hand, it is more difficult to evaluate and, on the other hand, small variations in the site may bring important variations in the wind resource.

\section{-Wind Resource Assessment Methods}

There are a variety of methods to assess wind resource and they range from lower to higher costs. The methods of assessing the wind resource usually stem from using a general wind map and using that wind speed information to form the basis of a production estimate. Another approach is to use a commercial wind resource model to identify, more "precisely", the annual wind speed range. A third approach is to assess wind measurements from nearby projects, wind resource towers, airports, or other weather stations. Having equipment and tools that provide wind rose information are invaluable for the estimation of wind turbine production. Wind maps typically provide a basis for the wind speed, which is the other important factor in understanding production.

These three approaches do not take into account the impact of local micro-siting and the dramatic effect that it has on a small wind turbine. The only method where the wind resource is truly quantifiable and accounts for obstacle, terrain, wind direction, and blockages is to measure the wind at the exact location and exact hub height of the proposed small wind installation. Even though on-site wind measurements are the most reliable method of assessing the local wind resource, it is expensive and time-consuming and the cost is not justified for SWTs [16]. Historically the cost of wind measurement equipment and analysis has been prohibitive for small wind turbines. Recently new wind resource measurement approaches have been developed, including lower cost wind measurement equipment and towers and new drone technology [17].

Methods to cope with these cost restrictions are listed as follows: Using regional wind maps specifically for small wind turbines implementation, reanalysis data, or nearby Met office statistics; and choosing a site for the wind turbine as free from obstacles as possible.

\section{Using Reanalysis Data}

Given that the temporal variability of the wind, it important to know the time distribution over a period. Meteorological stations may be an option; however, they are not always close to the site or it is not possible to access their information. In that case, it is feasible to use reanalysis databases. Reanalysis data uses assimilation processes to combine observed (or measured) data obtained from satellites, ships, sensors, and weather stations with numerical models.

Since the observed data are unevenly distributed over the Earth, numerical meteorological models allow the estimation of the state of different layers of the atmosphere for a certain place and time period using a regular grid. With this approach, it is possible to 
generate a time series of gridded atmospheric parameters, such as air temperature, pressure, and wind at different altitudes; and surface parameters such as rainfall, soil moisture content, ocean-wave height, and sea-surface temperature. The three leading global data sets and its most recent bases are described below [18]:

- CFSR: This is the Climate Forecast System Reanalysis. Based on the Climate Forecast System, the NCEP global forecast model spans from 1979 to the present year. Most parameters are available every $6 \mathrm{~h}$, whereas selected variables are available every hour. CFSRv2 provides wind speed and wind direction at $10 \mathrm{~m}$ above surface, with a horizontal resolution of $38 \mathrm{~km}$.

- MERRA: MERRA is the Modern-Era Retrospective Analysis for Research and Applications, Version 2, based on the National Aeronautics and Space Administration (NASA) global data assimilation system (GEOS-5). MERRA-2 provides wind speed and direction at $50 \mathrm{~m}$ above surface. It holds one hourly values in a period from 1992 until present and a horizontal resolution of $50 \mathrm{~km}\left(0.5^{\circ}\right.$ latitude and $0.625^{\circ}$ longitude). Hourly data for solar irradiation and wind speed can be accessed freely in the web service [19].

- ERA5: ERA5 is the fifth generation European Center for Medium-Range Prediction (ECMWF) atmospheric reanalysis of the global climate. It is a set of climate reanalysis data from 1979 to the present year developed by the Copernicus Climate Change Service (C3S) and processed by the ECMWF. ERA5 provides wind speed and wind direction at $10 \mathrm{~m}$ and $100 \mathrm{~m}$ above surface, with a special resolution of $31 \mathrm{~km}$ [20]. In the case of ERA5, data assimilation is performed every $12 \mathrm{~h}$. However, it provides hourly estimations because the assimilation method takes into account the exact moment of the observations and the evolution of the model within the assimilation window.

Using reanalysis data also allows the easy performance of long term analysis on the viability of the inclusion of wind generation in hybrid diesel microgrid as data for decades.

\section{- Small Wind Resource Assessment}

These databases have the advantage of having a high percentage of availability; however, they are not influenced by local effects of orography and roughness. Since roughness measures the decrease in wind speed due to friction with the surface and orography generating alterations in the wind flow, it is necessary to take them into account so that the energy assessment of the winds is as representative as possible of the site.

Using these global datasets to generate initial and boundary conditions for the simulations, some mesoscale and/or microscale models may produce higher resolution grids, such as WAsP ([21]). The most common mesoscale model is WRF [22], which is a weather prediction system used to generate meteorological forecasts or hindcasts. WRF downscales the global datasets and the results can be used to generate spatial wind maps and as a valuable source of long-term time series wind data. The WRF grid and output resolution is typically a few kilometers and ca. $3 \mathrm{~km}$ is often the preferred choice. It is possible to downscale the data from the global level to the mesoscale level and, further, to the microscale level, which is usually offered by commercial tools (as those from EMD or UL) with proprietary microscale models [23].

However, small wind turbines are often installed under wind conditions far from the conditions specified in standards and this is expected to result in large power curve uncertainties [17].

Complex terrain sites are typical small wind turbine sites and pose another challenge in accurately estimating wind turbine production. Underproduction was originally believed to be dominantly due to uncertified turbines and inconsistent turbine rating approaches; but as more turbines have become certified and wind turbine ratings are more globally consistent, underproduction is believed to be a strong function of the local micro wind conditions [16].

Over time, new modeling tools, site assessment technology, and study methodologies will evolve. Without streamlined customer-friendly approaches, the small wind turbine 
market will continue to be a smaller niche market. Better site assessment can be a step toward easing owner purchase decisions [16].

This paper is proposed for that aim.

(b) Existing Technology

There does not exist a unique definition for what a SWT is, in terms of size, but a more or less universal convention is that it refers to wind turbines smaller than $100 \mathrm{~kW}$. Within this range, some classification can be made according to Table 2.

Table 2. Classification of SWT (Source: CIEMAT).

\begin{tabular}{ccc}
\hline Rated Power $\mathbf{( k W )}$ & Rotor Swept Area $\mathbf{( m}^{\mathbf{2}} \mathbf{)}$ & Sub-Category \\
\hline Prated $<1 \mathrm{~kW}$ & $\mathrm{~A}<4.9 \mathrm{~m}^{2}$ & Pico wind \\
\hline $1 \mathrm{~kW}<$ Prated $<7 \mathrm{~kW}$ & $\mathrm{~A}<40 \mathrm{~m}^{2}$ & Micro wind \\
\hline $7 \mathrm{~kW}<$ Prated $<50 \mathrm{~kW}$ & $\mathrm{~A}<200 \mathrm{~m}^{2}$ & Mini wind \\
\hline $50 \mathrm{~kW}<$ Prated $<100 \mathrm{~kW}$ & $\mathrm{~A}<300 \mathrm{~m}^{2}$ & (No clear definition adopted yet) \\
\hline
\end{tabular}

The values that define the ranges for this classification have been chosen from the norms and legislation affecting SWTs. The value of $40 \mathrm{~m}^{2}$ was the limit established in the first edition of the IEC-61400-2 standard and is the range intended at the present time for the integration of SWT into the built environment; the $200 \mathrm{~m}^{2}$ limit was established in the second edition of the above mentioned IEC-61400-2 standard in 2006 and includes most SWT applications. Finally, the limit of $100 \mathrm{~kW}$ is defined in many countries as the maximum power that can be connected directly to the low voltage grid. The pico-wind range is commonly accepted as those SWTs smaller than $1 \mathrm{~kW}$ [24].

Despite being more uncertain, models and topographical background data are at a level of quality that makes the calculated wind resources valuable for SWT projects. Having determined the wind resources, the second source of uncertainty in energy yield calculations is the wind turbine type or more specifically the power curve of the wind turbine. Many countries today have standards for how wind turbine manufacturers should collect and process data to produce certified power curves; this improves the accuracy of the power curves that could otherwise be too "optimistic" [18].

Quality assurance has proven to be indispensable for establishing an enabling environment for a rapid uptake of renewable energy technologies. Quality assurance of standards are intended to ensure that products and services perform as expected and also includes the mechanisms to verify that such requirements are fulfilled, e.g., testing and certification [25]. This is of particular importance for SWT: A great effort has been conducted during the last two decades to increase the SWT quality and there are many reliable models in the market, but it is also possible to find many commercial models that have not been certified nor tested. A description of norms and standards affecting SWT can be found in [25] but, in general, an effort should be made to work with, at least, independently tested SWT. In [26], some guidelines can be found to assure quality for buying SWTs safely, which covers the manufacturer, the product reviews, the warranty, testing and certification and the installer.

Another important issue related to SWTs is the availability of wind turbines, which refers to both the available sizes and the available manufacturers. Before choosing a small wind turbine, it is advisable to be informed about sizes and maintenance support service in the area. This limits the number of available wind turbines for the design. An added difficulty is the highly changing characteristic of the SWT market (as an example, from the around 20 small wind turbines manufacturers in Spain in 2014, only eight are still active in this field in 2020 [27]). Information on available manufacturers and models should be updated frequently in order to be aware of the present situation. Both myWindTurbine [28] and HOMER Pro [29] include SWT databases, which are useful as a reference, but both of them are neither completely updated nor exhaustive. The reference, [30], may be a good starting point. 
The last issue that will be highlighted here is the cost of the SWT. On one hand, there is a great variety in the cost of similar size commercial SWT: Cost should not be the only criterion to choose a SWT because, as it was mentioned before, not all of them will be of the same quality. On the other hand, the information on the cost of a particular SWT is not always easily accessible: Of course, the best method is always to have a particularized (the cost may be different according to the site) quote from the manufacturer/installer but some general references can be found in literature for a first approach [31-33].

\section{(c) Availability of Design Tools}

In general, when talking about available power systems design tools, there are different approaches depending on the following factors:

- Level of detail of the design, which is also related to the stage of the design of the project. When little detail is necessary, such as in the concept design phase, simple spreadsheet-type tools can be used, whereas dedicated tools are needed for a more detailed analysis, such as in the feasibility study stage. HOMER Pro is an international reference covering most of the levels of detail up to the feasibility study.

- Technologies involved: For example, whereas DPS are usually designed as a function of maximum and minimum power in the loads, REDPS usually takes into account the energy balance for their sizing, covering of course the power needs.

- Spatial resolution: Centralized REDPS can be designed with a unique profile for each RE resources and even a unique load profile (even if there are distributed loads, the generating system can be designed with a unique load and design the distribution lines), whereas distributed REDPS may require different profiles if distances are long enough. In this case, particular tools may be needed, including some Geographical Information System.

- Time resolution: different configurations of REDPS (see Section 2.1.2) require different time resolutions analysis. All of them require energy balance analysis, which are minimum monthly and preferably in a hourly time resolution, for the optimization design. Furthermore, diesel dominated architectures require dynamic analysis in the case of medium and high percentage RE systems. An example of used tools for a WDPS with high RE percentage is shown in Figure 2.

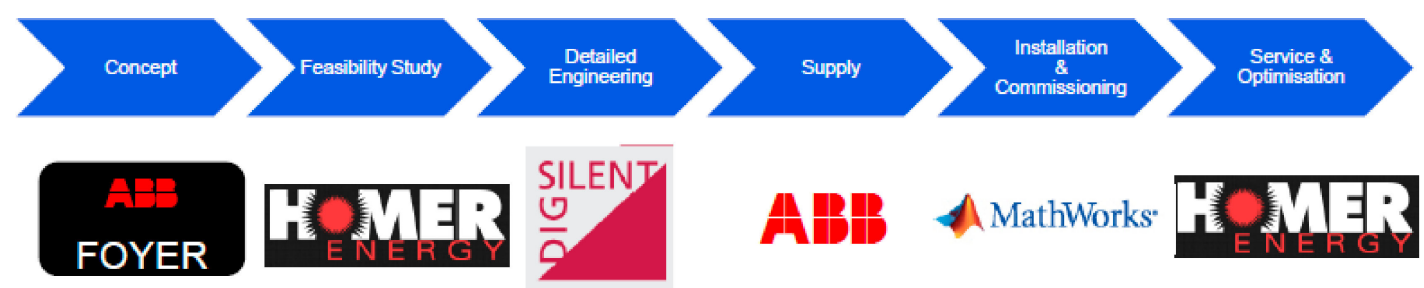

Figure 2. Example of tools used for a high RE penetration REDPS in the different design stages [34].

In the case of the selected configuration for this paper, dynamic analysis is not necessary for inverter dominated systems with one main diesel generator and with long term (several hours at least) electrochemical storage as the battery and the battery converter are able to maintain short term stability.

There is a great variety of sizing tools for PV Hybrid systems [35] but the number is limited when including wind generation in the system. Fortunately, even though the number of tools for PV-Wind REDPS design is limited, there are some high-quality available tools. According to a comparative study of 68 computer tools for the integration of renewable resource in various energy systems, HOMER was evaluated as one of the most applicable for optimization, feasibility, and sensitivity analysis of both off-grid and grid connected micro power systems and also pointed out as the most used and best known of all the software tools developed so far [8]. 
In particular, HOMER Pro has become a standard in the design of REDPS, as it merges most of the capabilities for a feasibility study in a single tool and it also includes wind technology (other well-known tools for PV systems design, such as PVSYST, does not); thus, it is the recommended tool for the configurations under study in this work. However, nowadays HOMER Pro software is no longer free (previously, there was a Legacy free version) and some amount must be paid depending on the desired use.

\subsubsection{Methodology to Account for Small Wind Turbines Barriers during the Design Process}

In the first place, the methodology described here deals only with some technical considerations of the design related to the consideration of wind technology; the development and management of a REDPS system is a relatively long and complicated process and involves other key aspects such as social, environmental, management, contractual, quality assurance, training, and some other aspects. These aspects obviously have to be taken into account through the project development, but are out of the scope of this work due to time and space limitations. Some useful references may be in [36,37].

As presented in Section 2.1.2, an adaptation has been made to cope with those particular issues that arises in REDPS systems during the consideration of wind technology, concluding with some suggestions that basically include the following stages.

\section{(a) Data Collection}

At this stage, the main inputs to the design process are gathered: topographic information, renewable resources (with special attention to wind resource, which is usually more difficult to evaluate), consumption characterization (crucial), and technical and economic information of the equipment. In projects of a certain size, it is a common practice to carry out field campaigns for both the wind resource and the consumption characterization [38].

In the case of performing a measuring campaign, in order to summarize the high quality requirements in wind measurement, international standards have been developed, such as the MEASNET guidelines. MEASNET is an international network of measurement institutes, which developed the guideline "Evaluation of site-specific wind conditions". This guideline describes the process of site assessment including data collection, evaluation, and interpretation. The MEASNET guideline refers to IEC 61400-12-1 and focuses on data quality, plausibility, and integrity [39].

Even for SWT there are some guidelines available for site assessment, such as [40], that covers most of the aspects that may apply when considering the inclusion of a SWT in a system. More detailed guidelines for site turbulence influence on the SWT estimated production can be found in dedicated guidelines, such as [15], for example.

However, one of the main limitations for taking into account wind generation in REDPS in the range that is being considered in this work is commonly the lack of reliable wind data necessary to evaluate its convenience. Nowadays, there are both global and local (usually at a national level) wind atlases. In this case, the no-data situation, which was not rare a few years ago, is almost extinguished. However, in order to perform a minimum performance evaluation of wind generation within a REDPS, it is not the case that any wind resource characterization will be valid: characterization needs to include spatial and temporal information in the most detailed possible manner. It should be remembered here that, of course, the best method to achieve this goal is an on-site wind measurement campaign, but it is precisely the case of not having this campaign that it is being covered at this point.

At least hourly average wind speed variation is needed to be able to assess the wind generation in a REDPS in order to evaluate its matching with load and other forms of generation profiles from an energy balance point of view. Other short-term phenomena (dynamics and/or transients) would require even higher time resolutions, but they are out of the scope of this particular application since there is long-term storage.

Global and local wind atlases may only bring information on the overall yearly wind regime [41] or even on the monthly average wind speed [42]. In the latter, some software 
(such as HOMER Pro) may generate hourly synthetic series from monthly average values of wind speed, so they might be a first approach. For the site assessment, wind direction estimation is also necessary. Global Wind Atlas [41] provides an overall wind rose.

The news on this topic is the availability of reanalysis data derived from satellite observations are described in Section 2.1.3 (a) in this paper, both globally and freely, and provides relatively sufficient time resolution (one hour) wind speed and wind direction data but with an insufficient spatial resolution of several square kilometers. However, there is a possibility to use these data as an input for downscaling (considering also the available information on roughness and DEM, Digital Elevation Models) by generating higher spatial resolutions down to several hundred meters. Although all these sources of information are freely available so that anyone could produce these results (these are good news for SWT), some commercial tools exist that allow performing it in an easier manner. As a reference, EMD in Europe and UL in the US offer different software solutions to obtain hourly wind resource estimation for any point (Windographer and WindNavigator, in the case of UL; WindPro, for EMD) with a reasonable spatial resolution: UL offers a Typical Year Time Series Short term data set using the AWST MASS model and scaled to $200 \mathrm{~m}$ resolution to represent a 365 day sample from a 15 year period [22], while with EMD's full windPRO modeling chain, it is possible to downscale the data from the global level to the mesoscale level and, further, to the microscale level (e.g., using the windPRO scaler options) to a $250 \mathrm{~m}$ resolution or even $100 \mathrm{~m}$ resolution with WAsP [21].

These two software groups also offer two particular applications that are especially suitable for the assessment of SWT in REDPS: myWindTurbine (EMD, [28]) was designed for the evaluation of the influence of obstacles in SWT production which, as it was mentioned in Section 2.1.3 (a), is a key issue for SWT; and HOMER Pro (recently acquired by UL, [29]), which is the reference for REDPS optimization, as it described in Section 2.1.3 (c). In its latest version of HOMER Pro 3.14.2 (10 August 2020), there is a link to WindNavigator ([43], UL software for wind resource estimation) that, while it is not yet available, opens the door to connect both applications.

One estimate of the cost to have a site modeled in the United States in 2016 was approximately $\$ 500$. The model utilizes static wind maps, which is a gross approximation using annual average site wind speed and micro-site adjustments [17]. A characterization using myWindTurbine software costs around 60 EUR/site [28]. However, care should be taken with respect to the temporal needs in REDPS previously described, which may not be covered by these solutions.

\section{(b) Sizing study}

It is advisable to perform an initial screening of the components sizes at a simple spreadsheet level and at a conceptual design level: It is convenient to prepare the information for its use in the sizing tool (HOMER Pro is proposed, which in the last versions incorporates the Optimizer, and the automatic tool to search for the optimal configuration) and also it is convenient to have an estimate of the results. This spreadsheet may also be useful if a business model analysis is required, as HOMER Pro does not include it.

However, sizing tools require higher possibilities, such as the following: hourly basis simulation, which usually requires synthetic generation of data to compensate the possible lack of measured data; sensibility analysis, to cope with uncertainty of the inputs; more detailed (but still friendly) models of components, including all the necessary parameters to accomplish the study but at the lowest degree of complexity in order to make it useful; databases of commercial components, with the capability to create new ones.

At this level, both options of tools are available: commercial tools (either free or requiring a fee), such as HOMER PRO tool from Homer Energy by UL company, is an international reference; or self-designed proprietary tools, which take time and effort to develop but may be necessary if a specific analysis has to be made.

Real dynamic analysis is not usually necessary for these type of systems as they used to be inverter dominated microgrids based on a long-term battery using commercial power electronics solutions, which provide the necessary power quality and electrical stability 
to the system. However, it is convenient to implement this pseudo-dynamic analysis to assess the behavior of the battery through the simulation, mainly taking into account the influence of wind generation, as it was mentioned in Section 3.1. Whether this analysis is performed is up to the designer for establishing the stability of the system since the feasibility study does not cope with this issue.

The output of this stage in the design is a detailed behavior of the selected configuration in terms of stability and performance; the designer has to decide whether it is as expected or not (if not, then the designer would have to go back and make the necessary corrections on the configuration).

\section{(c) Implementation Project}

Once the configuration and equipment are settled, all of the components of the system are calculated and chosen through the "Sizing study" stage and it is time to prepare the necessary technical documentation for the deployment of the installation: schemes, plans, etc. This is purely an engineering stage; there is no dedicated software for this step, but programs of general use in engineering are commonly applied. However, some technology specific software may be necessary: for example, in order to design the PV generator (if it is present in the design), it is necessary to design the detailed configuration of the generator, which is not provided by HOMER Pro.

Even though this stage will not be covered in this paper, here are some hints in the case that some wind generation is present in the final design:

- Installation issues: foundation design; need and availability of a crane (which is related to the height and type of tower); available space. Manufacturer/installer should help with (or perform) this part.

- Electrical equipment: decide whether to use AC or DC coupling; power converter availability for the selected SWT and for the specific use; voltage and frequency (nominal value and range).

- Control issues: communication with the system control; dump load regulation (high temperatures), compatibility with Li-ion batteries (if present).

- Quality assurance: as it was described in Section 2.1.3 (b), all the related issues (guarantees and warranties, $\mathrm{O}$ and $\mathrm{M}, \ldots$ ) should be established.

It is worth talking, at this point, about the assessment of the installation. There is not enough experience on PV-Wind REDPS nowadays and it is important to make a provision for the monitoring system and its assessment. In reference [44], a new approach and a case study of a PV-wind hybrid system performance analysis is presented.

\subsection{Materials: Case Study}

The proposed methodology to account for the small wind turbines barriers during the design process has been applied on a real case appearing in Uruguay. The National utility (UTE) is in charge of an existing PVDPS deployed several years ago in order to reduce fuel consumption on the previously existing DPS. After several years of exploitation of the PVDPS, recently there was an interest from the utility in considering the inclusion of wind generation to increase both renewable energy penetration and load consumption. However, even though the UTE had been able to cope with the promotion and installation of the existing PV-Hybrid system, they faced the difficulties that including wind generation would bring, which demanded CIEMAT's experience in this field: this is how this real case study appeared.

In this section, the case study will be presented, showing the performance of the existing PVDPS through the analysis of data coming from the monitoring system as well. The application of the results derived from the use of the presented methodology will be shown in next Section 3. 


\subsubsection{Description of the Case Study: An Existing PVDPS in Cerros de Vera, Uruguay}

Cerros de Vera is located in the northwest of Uruguay (Municipality of Salto), with approximately 70 electricity home services. Cerros de Vera is a small village that has been developed thanks to the support of MEVIR, an organization that works to eradicate unhealthy housing for rural workers by facilitating the construction and renovation of homes and access to community services. Since the village is not connected to the national grid, initially, the electrification was based on diesel generators. However, in February 2014, the town incorporated solar energy into its electrification system, becoming the first isolated rural village in Uruguay to be autonomously supplied with renewable energy.

The power system has an installed solar PV power capacity of $52.2 \mathrm{kWp}$ (180 Suntech $290 \mathrm{Wp}$ modules), two Kohler J88 diesel generators (64 kW each), and two battery banks (48 V, BAE made) with an overall storage capacity $\left(\mathrm{C}_{10}\right)$ of circa $300 \mathrm{kWh}$. The solar PV generator is divided into three groups, each one connected through a SMA Sunny Tripower inverter ( $17 \mathrm{~kW}$ each) to the $0.4 \mathrm{kV}$ three-phase $\mathrm{AC}$ microgrid established by the two groups of three SMA Sunny Island $8.0 \mathrm{H}$ power converters $(3 \times 8 \mathrm{~kW}$ each group). The average daily energy demand is around $440 \mathrm{kWh} /$ day and the maximum demand is approximately $45 \mathrm{~kW}$. In Figure 3, the general layout of the system is depicted. In Appendix A, some pictures of the system and its components are shown.

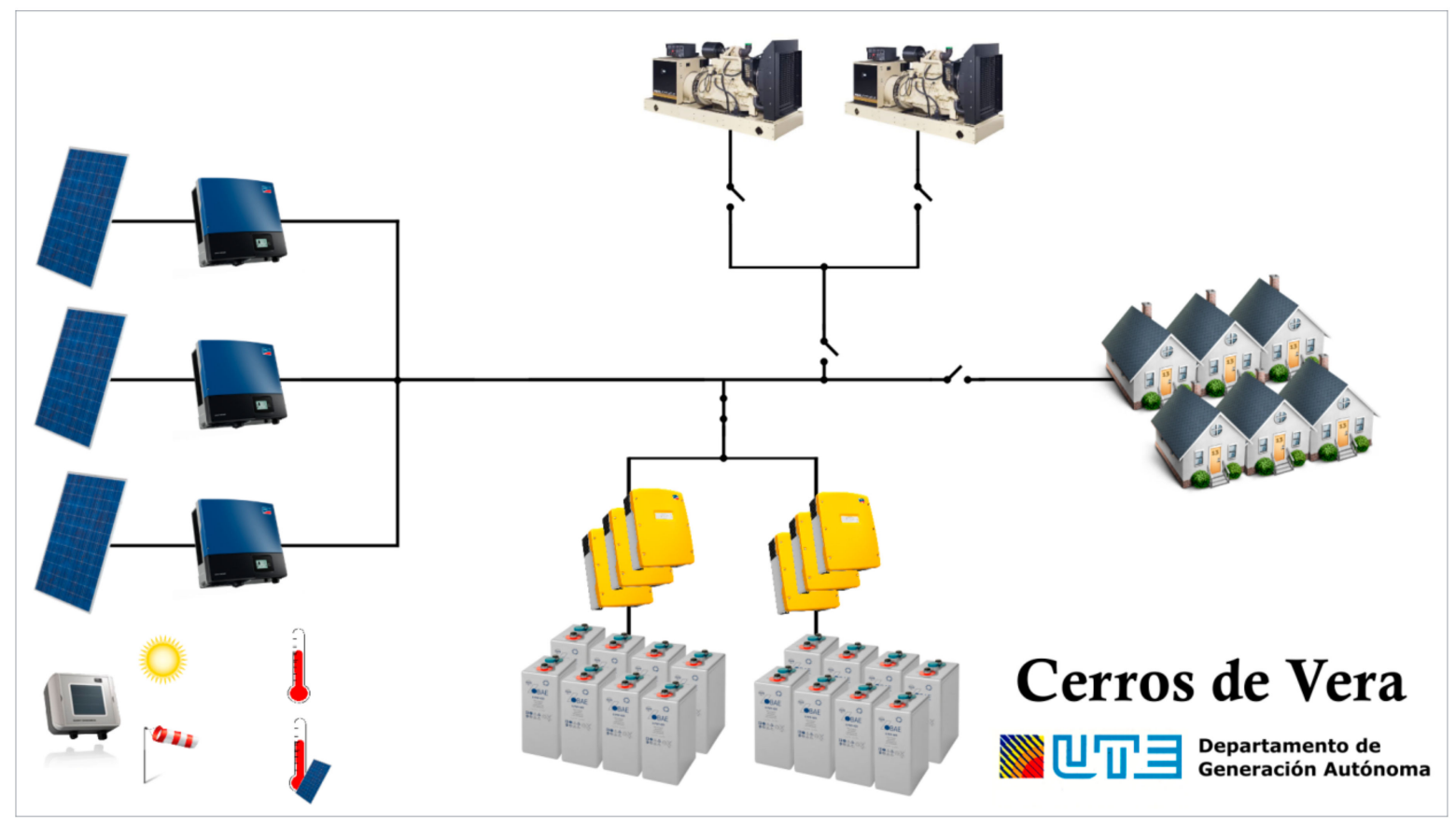

Figure 3. General layout of system under study, an existing PVDPS in Cerros de Vera, Uruguay.

\subsubsection{Description of the Operation of the Existing System}

The system is monitored through a weather station (connected to an SMA Sunny SensorBox) and the measurements are obtained from the power converters. Along with these measurements, the utility measures the energy consumption independently. From all these devices, data from 2018 and 2019 are available. After quality control of these data, a one year period from July 2018 to June 2019 was selected for evaluation. Sampling rate of data is $5 \mathrm{~min}$ for the raw data. A description of the system based on these data is shown now.

- Load Characterization. 
From the measured data, the load patterns were assessed. In Figure 4, monthly (quite flat) and average hourly (peak in the nighttime) profiles derived from the measurements are shown, encouraging the hybridization of resources.

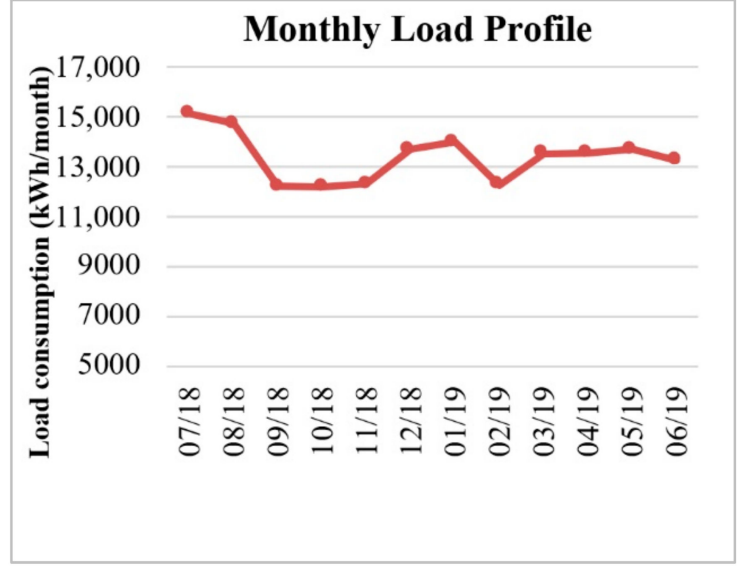

(a)

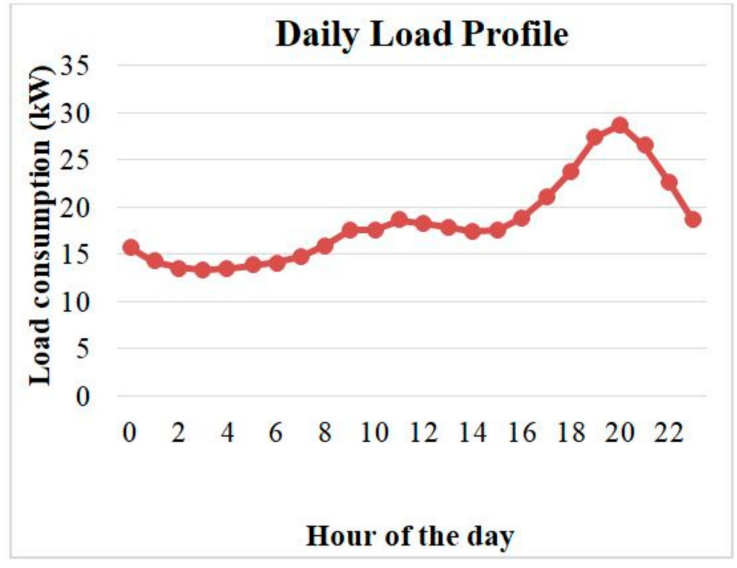

(b)

Figure 4. (a) Total monthly load consumption variation through a year; (b) average hourly load profile.

- Solar resource.

The weather station includes solar radiation measurements. From the measured data, the solar resource on-site has been derived, as shown in Figure 5. However, a validation of this resource has been made using available databases, as described later in the Data collection chapter.

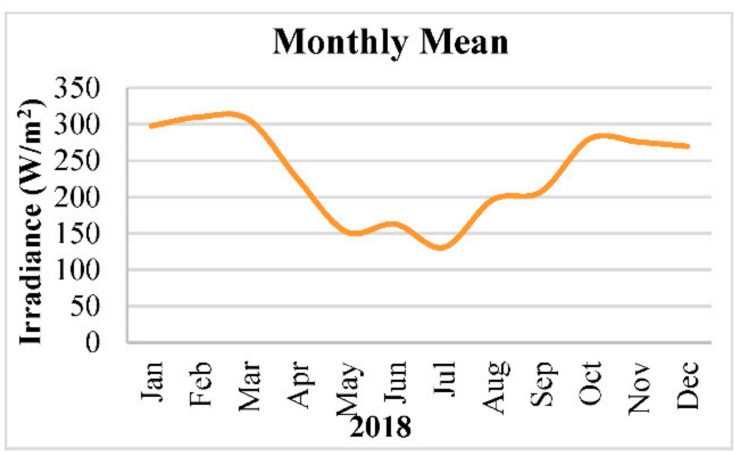

(a)

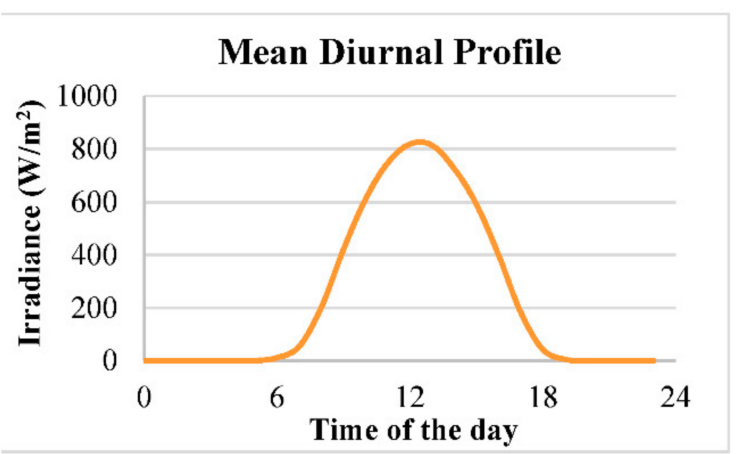

(b)

Figure 5. Average solar radiation variation (a) through a year; (b) hourly profile.

- Wind Resource.

The weather station also includes wind speed measurement, for solar PV generation purposes (not for wind generation purposes). The very low measured data in this case most probably will not be representative for wind resource assessment. In Figure 6, the measured results are shown and the validation of this resource is described later in the Data collection Section 3.1. 


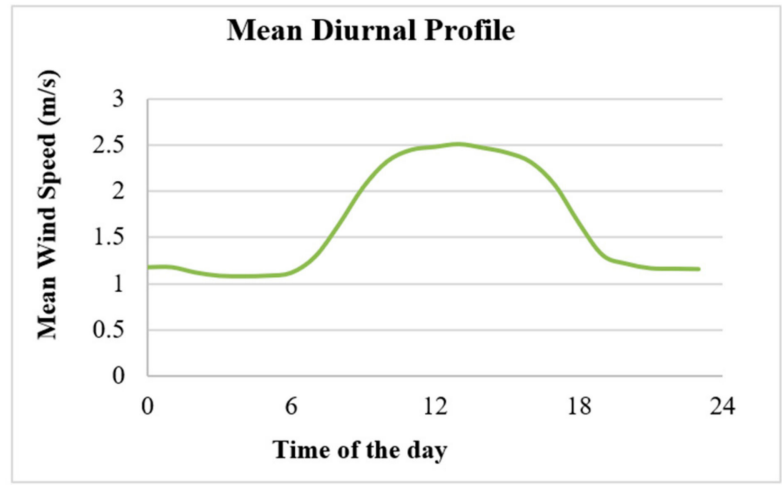

(a)

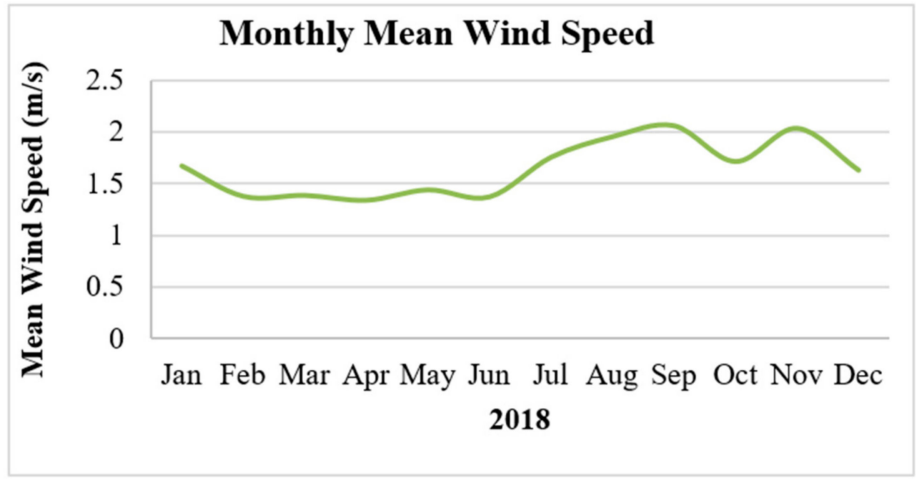

(b)

Figure 6. Wind speed average variation: (a) hourly profile; (b) through a year.

- Photovoltaic system.

The measured data for the solar PV generator show an overall annual production of 64.4 MWh which, for a $52.2 \mathrm{kWp}$ generator, represents 1233 equivalent hours. The measured performance ratio derived from measurements is $77.2 \%$. This low value is explained because of the regulation of solar PV generation when the batteries are fully charged, as can be seen in the Figure 7.

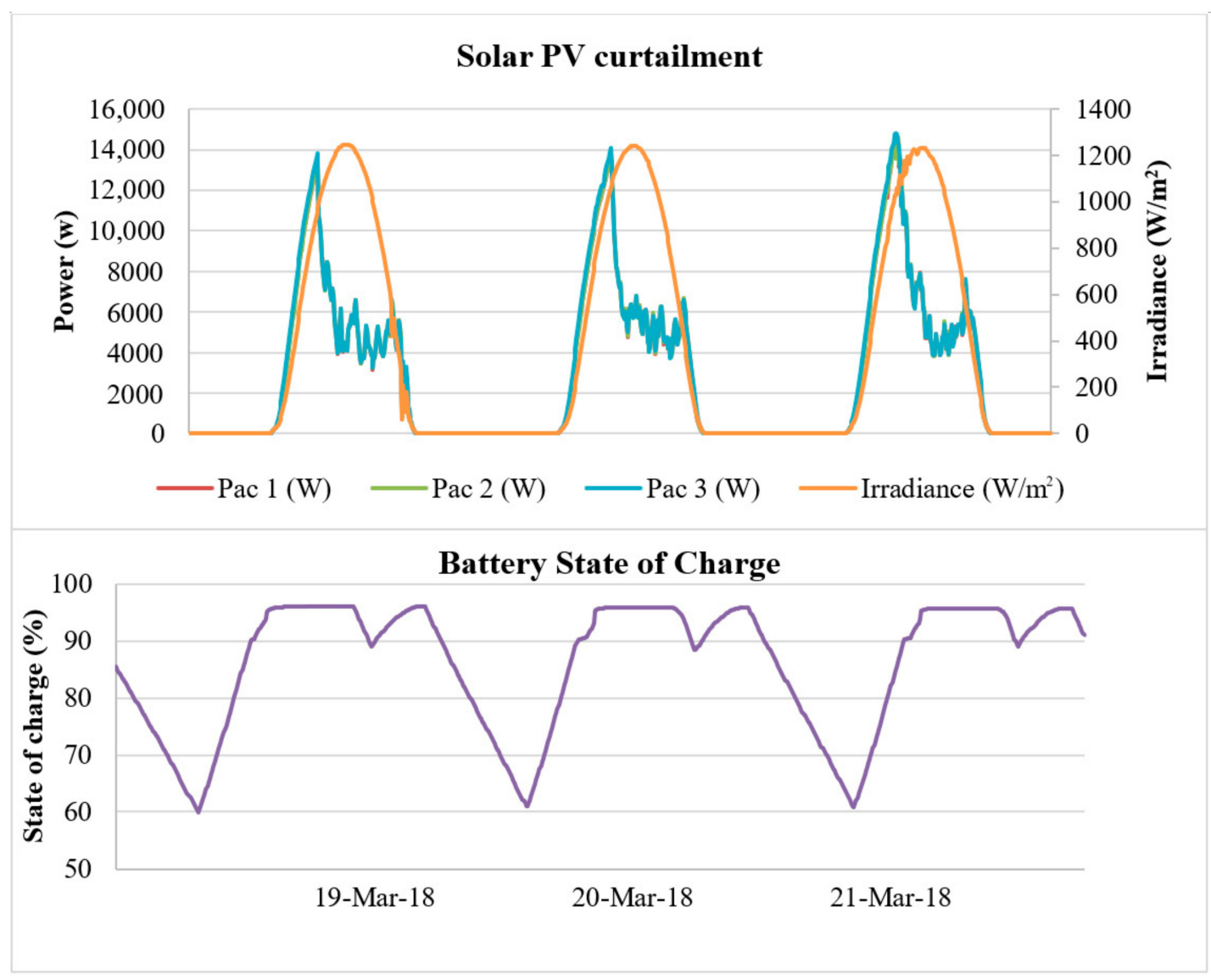

Figure 7. Solar PV curtailment when the battery is fully charged and are derived from measurements. 


\section{- Converters.}

Both the overall average energy efficiency of the inverter and the rectifier have been calculated. The average values obtained are $92.33 \%$ and $89.71 \%$, respectively $(95.8 \%$ is the maximum efficiency in the specification sheets).

\section{- $\quad$ Batteries.}

The average efficiency has been calculated based on the energy received during charging and the energy delivered during discharge. As a result, an average efficiency of $77.1 \%$ has been obtained.

\section{- Diesel generator.}

Although there are two generators, only one of them works and the other one is used as a backup in case of breakdown. The system's current operating situation results in $40 \%$ of the energy generated resulting from solar energy, with diesel generators operating an average of $8 \mathrm{~h}$ a day. This implies a significant reduction in fuel consumption, but also in engine maintenance and extension of their useful life. Due to the facility's design, the quality of service provided to the population was not affected.

\section{Results: Application of the Proposed Methodology to the Case Study}

In this section, the analysis of including wind generation in the existing system in Cerros de Vera will be covered using the proposed methodology. The application of the proposed methodology to the Cerros de Vera case study has been developed in three stages to analyze the feasibility of adding wind energy into the existing electrification system. The stages are: data collection, simulation of the operation of the current electrification system, and the generation and selection of future alternatives. They are sketched in the following diagram in Figure 8 and they will be described in the following subsections.

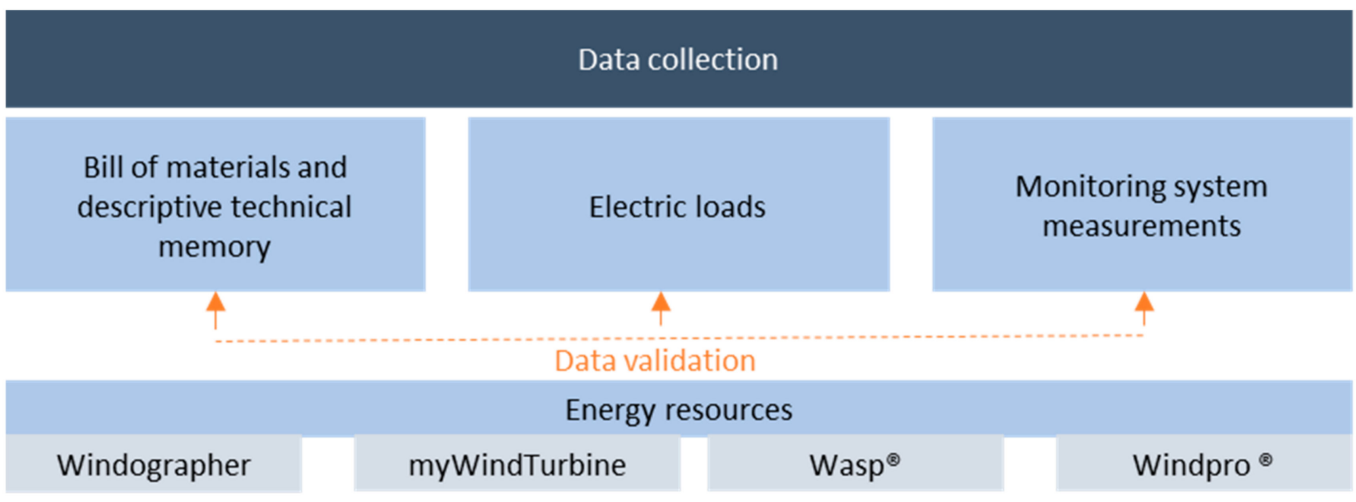

System operation

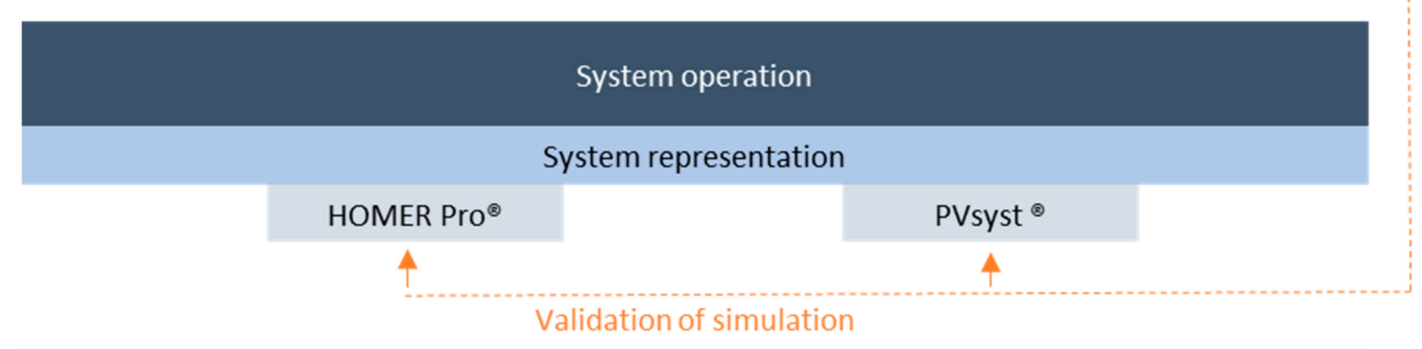

Future Electrification configurations

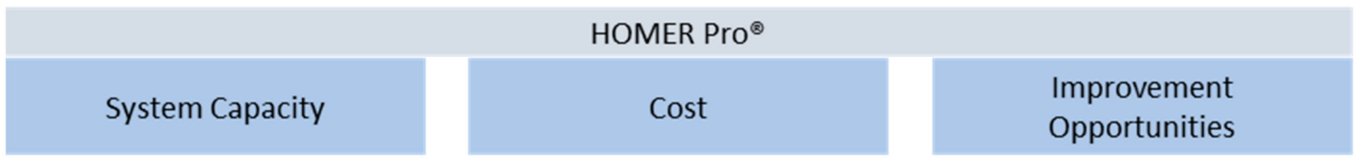

Figure 8. Flow chart for the proposed methodology applied to the case study. 


\subsection{Data Collection}

The purpose of this stage is to collect objective information for the village necessary to perform the study. Since the case study is an existing project, sources for the collection of data are two-fold: most of the input data comes from equipment measurements developed in collaboration with utility UTE; on the other hand, public databases have been used to validate existing data, to gather data for optimization and, most important in this work, data for the inclusion of wind generation.

- Load demand data.

15-min records of active power consumption in the town have been obtained. Based on the data, the daily consumption curve, the annual profile, and the peak power have been calculated, as it was described in the previous chapter (see for example Figure 4).

- Solar resource.

The solar radiation is measured at the weather station installed. However, a validation with the following databases has been made: Meteonorm, PVgis, Tacuarenmbó, the nearest meteorological station, and TMY of Salto database. In the following graph in Figure 9, it can be seen how the data measured in the meteorological unit (Met Stat. $24^{\circ}$ ) are higher than the values of the public databases consulted. This discrepancy was most probably due to the different slope but, thanks to the comparison of the energy produced vs. the estimated with the measured irradiance, it has been possible to rule out the discrepancy and validate the data measured by the meteorological unit for its use in the analysis. These data were summarized in Figure 5.

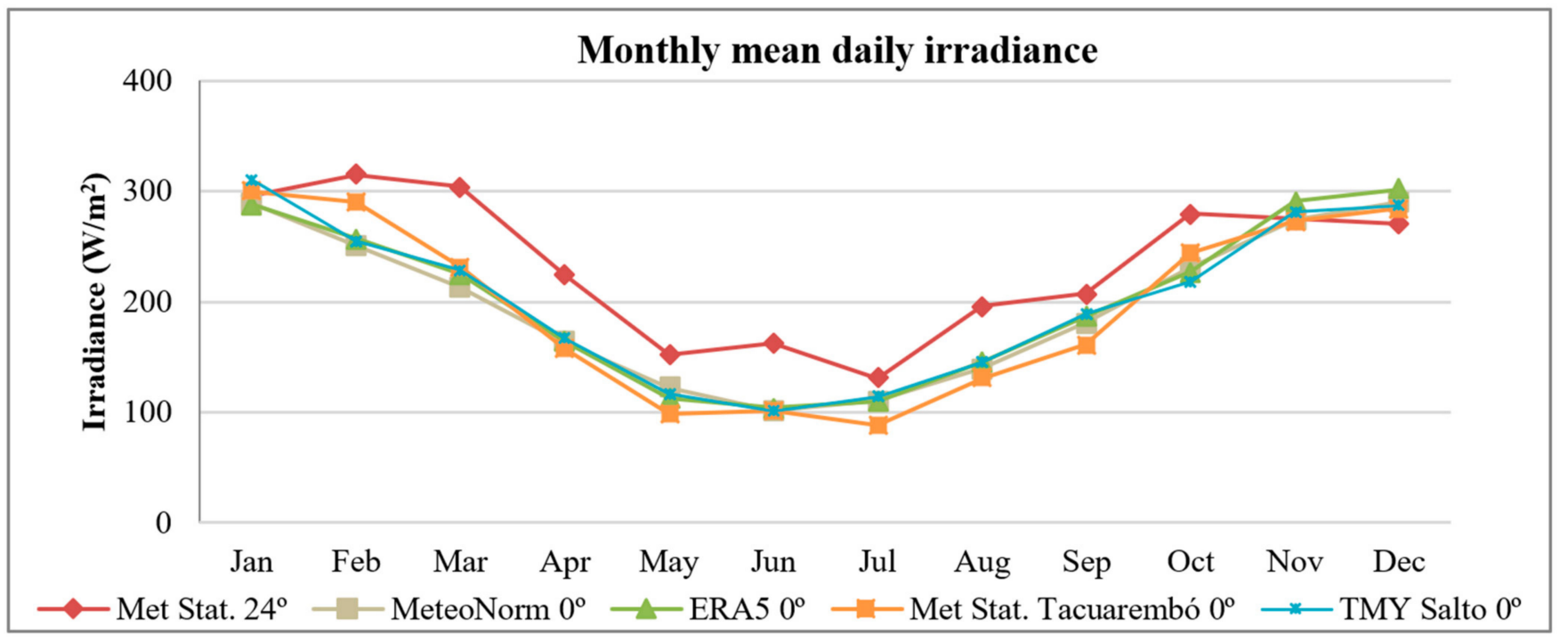

Figure 9. Comparison of measured data (Met. Stat. $24^{\circ}$ ) with databases (Meteonorm, ERA5, Tacuarembó Met. Stat., and TMY from Salto). Discrepancy comes from the different slope.

- Wind resource.

It was obtained from ERA5 database and downloaded with WindPro software. The selected node is located in 21S UTX 523,741 UTY 6,514,956. It is the closest to Cerro de Vera, with a distance of $12.8 \mathrm{~km}$. The series used includes the period 2010-2020, with hourly data for wind speed and wind direction at $10 \mathrm{~m}$, pressure, and temperature. Data obtained are not influenced by the local effects of orography and roughness.

The quality of the data obtained in the meteorological unit has been evaluated. Since the meteorological unit is designed to measure the variables that affect the photovoltaic installation, they have not been sufficient for characterizing the wind resource. These data have been supplemented with re-analysis databases. In order to evaluate the wind 
resource, two specialized programs in wind energy have been used; they include WAsP and WindPro.

Based on the ERA5 time series of wind at $10 \mathrm{~m}$ height, orography, and roughness, WAsP was used to perform a horizontal extrapolation that allows obtaining a resource grid. The grid has a resolution of $100 \mathrm{~m}$ (as the resolution of the used Digital Elevation Model is $90 \mathrm{~m}$ ), with 48,816 points calculated at $10 \mathrm{~m}$ height. In this manner, it is possible to identify areas with better resources and therefore with greater energy potential to place the wind turbine. The resource grid has been imported into Windpro to continue the analysis from that software. Figure 10 shows the resulting resource grid on Windpro, the location of Cerros de Vera and the location of the ERA5 node.

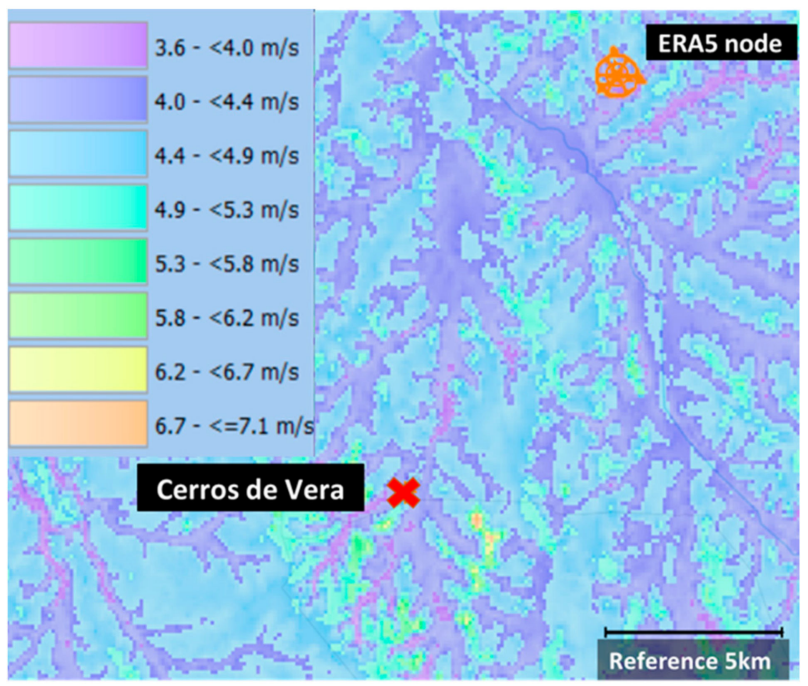

Figure 10. Resulting average wind speed at $10 \mathrm{~m}$ resource grid, with the location of Cerros de Vera on the bottom left and the location of the ERA5 node on the upper part.

- Temperature: obtained from ERA5 database along with wind data;

- Digital Elevation Model: obtained from SRTM 3 NASA database [45]. The downloaded map has an area of $40 \times 40 \mathrm{~km}$, with a $90 \mathrm{~m}$ spatial resolution. Additionally, a distance between contour lines of $5 \mathrm{~m}$ has been selected;

- Roughness: obtained from GlobalCover2009 -300 m database [46]. As for the orography, a $40 \times 40 \mathrm{~km}$ map was downloaded. As well as the ERA5 wind data, the orography and roughness have been downloaded through Windpro. These outputs have been considered as the input for the creation of the resource grid;

- Technical aspects of the current electrification system.

The compilation of information on the existing system from the detail of the components to the costs (initial investment, operation and maintenance, fuel, etc.) and the operational experience as well. UTE has provided most of this information.

\subsection{Simulation of the Operation of the Current Electrification System}

This stage is particular of this case study, as it is an existing system. In order to simulate the future behavior of the system, the parameters for the simulation are adjusted so that they reflect the present performance in a more accurate manner. This stage seeks to determine the operation of the system, checking it against the simulation results system based on the information collected described in the previous chapter. Should there not be any existing system, only simulation results would be available, derived from estimated (not measured) information. At this point, the data from the monitoring system provided by UTE have been used.

Since Cerros de Vera has a photovoltaic installation, in order to determine the operating mode of the system, two software tools have been used: PVsyst ${ }^{\circledR}$ and HOMER Pro ${ }^{\circledR}$. Since 
PVsyst ${ }^{\circledR}$ is a software specifically designed for photovoltaic systems, greater precision is expected for the simulation of photovoltaic production and for this reason the results of PVsyst ${ }^{\circledR}$ will be used as input data for HOMER Pro ${ }^{\circledR}$. The simulation of all system components will be carried out with HOMER Pro ${ }^{\circledR}$ using $1 \mathrm{~h}$ average data. Windographer ${ }^{\circledR}$ has also been used to process this information. The visual review of these data has allowed detecting anomalies in the operation of the different parts that will allow the improvement of the electrification system.

Below, after some first general considerations, the results obtained in the simulation for each of the components are described: photovoltaic system, converters, batteries, and diesel generator.

- General considerations.

The data provided by UTE for the load characterization have been compared with the monitoring system data.

The active power of the cluster and the photovoltaic power generated at the inverter output have been used to estimate the village's consumption. As a result, a difference of $1.54 \%$ has been obtained. In Figure 11, the comparison for 4 September with a minimum variation of $0.7 \%$ is shown.

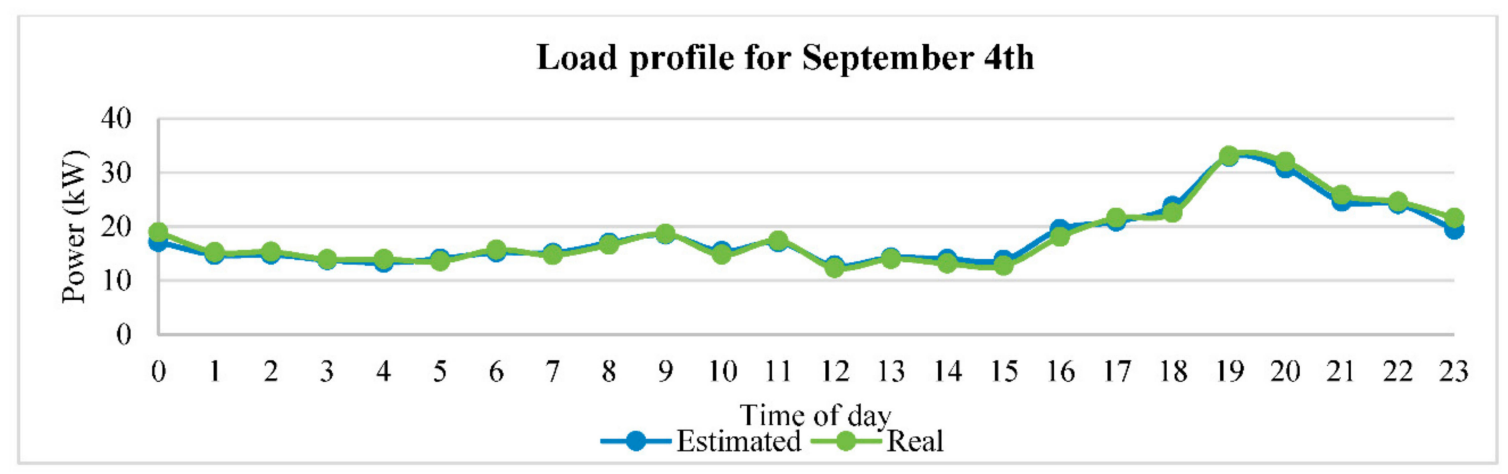

Figure 11. Comparison of load profiles according to the information provided by UTE meters (real) and by the power converters (estimated) for 4 September.

The consumption obtained from the data sent by UTE has been used as load input to HOMER Pro ${ }^{\circledR}$. Additionally, the components used and their respective costs have been defined.

- Photovoltaic system.

Since PV production in excess is curtailed, a simulation with PVsyst ${ }^{\circledR}$ has been carried out to obtain photovoltaic production capacity without the influence of curtailment. For this purpose, the parameters of the PV generator generation indicated in the previous section have been adjusted.

In order to estimate the operation of the installation without curtailment distortions, the average performance ratio has been calculated for irradiation values lower than $800 \mathrm{~W} / \mathrm{m}^{2}$ and a module temperature between 22 and $28^{\circ}$. As a result, a PR of $80.4 \%$ has been obtained. This value has been used as a reference to estimate different parameters in the PVsyst simulation.

The simulation results show an energy production at the inverter output of $84,912 \mathrm{kWh} /$ year, while the real energy produced was $64,403 \mathrm{kWh}$ /year.

To verify if the parameterization carried out in PVSYST ${ }^{\circledR}$ corresponds with the monitoring system data, a comparison has been made showing a good correlation for the times without regulation, as shown in Figure 12. 


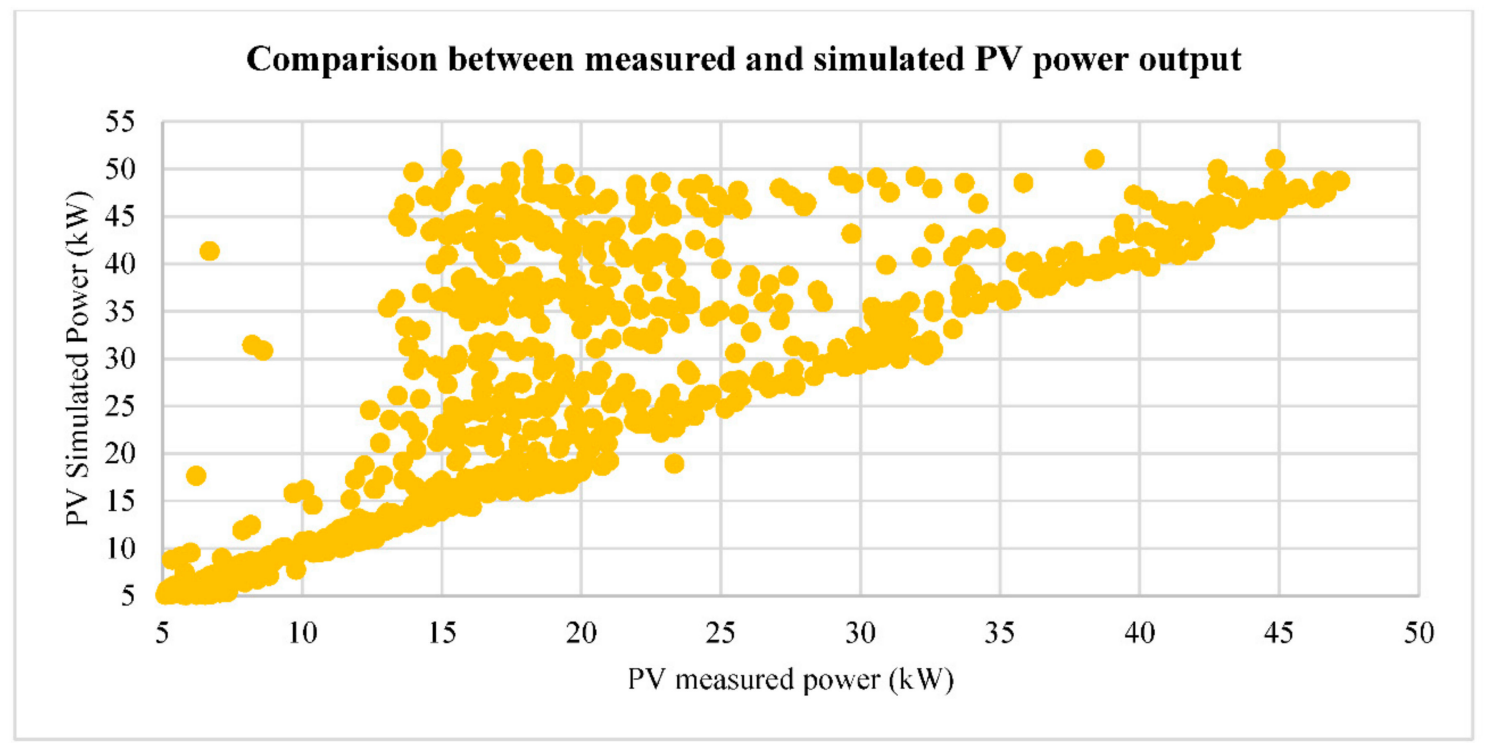

Figure 12. Comparison between the measured and simulated PV power output (points out of the linear correlation correspond to solar PV curtailment).

In order to compare the behavior of the rest of the components of the system, the generation corresponding to the real behavior, affected by the regulation, was kept as PV generation. However, in Section 3.3, corresponding to the optimization of the system, the production without curtailment has been analyzed in order to evaluate the possibilities for improvement.

The following comparisons are related to the period from October 2018 to December 2018.

- Converters.

As the Sunny Island $8.0 \mathrm{H}$ converter was not present in the HOMER Pro catalog, it was created. The average efficiencies for the inverter and rectifier were of $92.33 \%$ and $89.71 \%$, respectively, based on the current behavior calculated from the data of the monitoring system.

- Batteries.

Even though the installation was defined with a depth of discharge of $70 \%$, the value of $40 \%$ detected in the monitoring system for the validation period has been used. The battery efficiency has been considered $77.1 \%$ as calculated and the initial state of charge has been established at $97.87 \%$.

When comparing the results of the simulation in HOMER Pro with the monitoring system data, only a difference of $1.96 \%$ in the charge (battery + rectifier) and $2.94 \%$ (battery + inverter) in the discharge has been obtained.

- Diesel Generators.

Regarding the operating mode, the "Cycle Charging" option has been selected where the generator works at full load to supply the village's consumption and, in case of electricity surpluses, the battery charge is supplied. According to measured data, the diesel generator is automatically forced to work from 19 to $22 \mathrm{~h}$, independently of the state of charge of the battery to prevent the genset to automatically start during the night.

During the months from October to December, the energy delivered by the genset at the Cerros de Vera facility at the hours where data were available was $22,329 \mathrm{kWh}$, while the simulated power was $23,761 \mathrm{kWh}$, giving a difference of $6.41 \%$.

A summary of the results expressed above can be seen in Table 3: 
Table 3. Differences between the simulated and the measured results for the different components and for the validation period.

\begin{tabular}{cc}
\hline Component & Difference (\%) \\
\hline Photovoltaic system & $4.8 \%$ \\
\hline Converters + Batteries & $1.96 \%$ charge $/ 2.94 \%$ discharge \\
\hline Diesel Generators & $6.41 \%$ \\
\hline
\end{tabular}

Taking into account that the functioning strategy of the system is sometimes altered, according to measured data, these values are considered to be accurate enough, as it has been justified in this chapter.

\subsection{Analysis of Future Alternatives: Wind Generation}

An increase in the village loads and fuel consumption has been detected, triggering the following case study objectives: The analysis of the actual electrification system and the inclusion of wind energy in it. In this stage, the aim was to generate different electrification configurations considering what was evaluated in the previous points. Based on the technical and economic characteristics of the different alternatives obtained, this allowed the selection the optimal configuration. HOMER Pro has also been used at this stage. The design and analysis of the inclusion of wind generation to the current system in "Cerros de Vera" are detailed below.

\section{- Wind Turbine Site.}

Based on the analysis of the resource grid obtained from the ERA 5 wind data, which is detailed in Section 3.1, the wind turbine site has been selected. The criteria used was: wind resource and the proximity to the point of consumption and connections. Taking advantage of the fact that the photovoltaic installation has a security fence and enough space to locate the wind turbine inside, it has been decided to propose to place it within that area. The proposed site for the wind turbine is depicted in Figure 13.

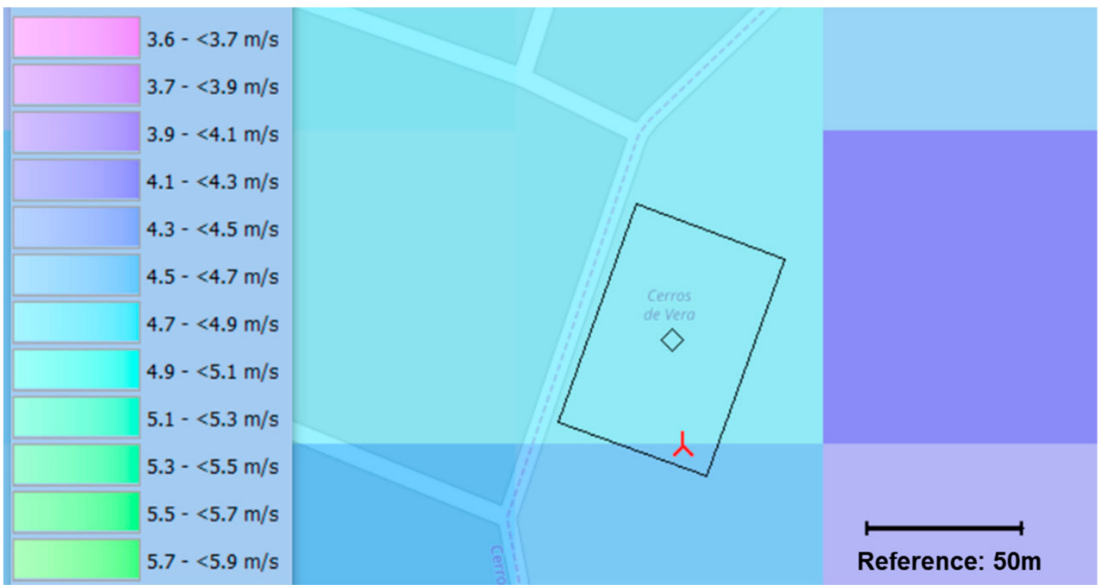

Figure 13. Resource grid at $10 \mathrm{~m}$ with the fence surrounding the solar PV area and the proposed location of the wind turbine.

- Influence of Obstacles.

In order to take into account the influence of the surrounding obstacles, the myWindTurbine software has been used, identifying the main obstacles and using the software to evaluate the losses due to them. In Figure 14, the general view of the site facing East and the predominant wind direction are shown, along with the main obstacles considered for their assessment. 


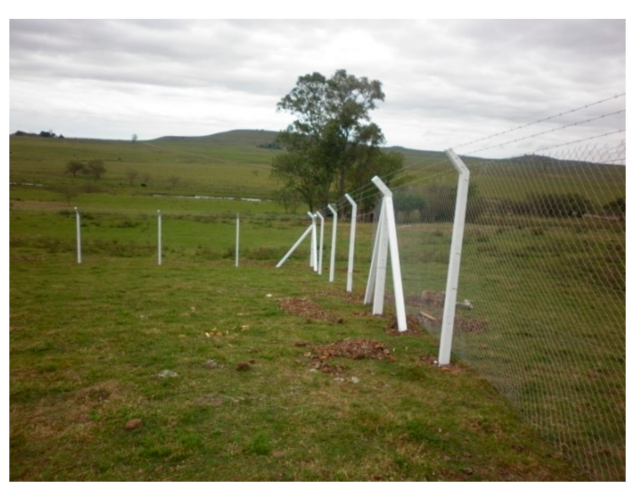

(a)

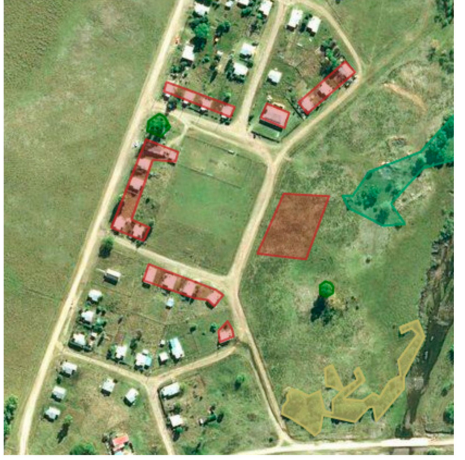

(b)

Figure 14. (a) General view to the predominant wind direction, East-Southeast; (b) Considered obstacles (in red).

The results of myWindTurbine analysis show a very small decrease in the annual energy production of $0.5 \%$ due to obstacles; the influence of obstacles will be neglected for this study.

- Wind Resource.

The wind resource assessment has been widely explained in the previous chapters. As a summary and neglecting the influence of obstacles in this case, according to the previous analysis the average speeds obtained in the site during 2019 for each month are detailed in Table 4 below and extrapolated at $24 \mathrm{~m}$ height using WAsP.

Table 4. Average monthly wind speed at the site at $24 \mathrm{~m}$ (extrapolated with WAsP from ERA5 $10 \mathrm{~m}$ height wind speed data).

\begin{tabular}{cccccccccccccc}
\hline Month & Jan & Feb & Mar & Apr & May & Jun & Jul & Aug & Sep & Oct & Nov & Dec & Annual Avg \\
\hline Wind Speed $(\mathrm{m} / \mathrm{s})$ & 5.43 & 4.84 & 5.23 & 4.91 & 5.22 & 5.44 & 5.48 & 6.03 & 5.45 & 6.07 & 5.34 & 4.65 & 5.35 \\
\hline
\end{tabular}

On the other hand, Figure 15 shows the wind rose obtained for the proposed site, showing East-Southeast as the clear predominant wind direction.

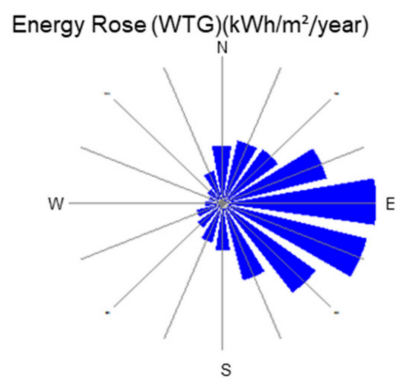

Figure 15. Wind rose on the proposed site showing East-Southeast as the predominant wind direction.

- Wind Turbine.

For the selection of the wind turbine, five wind turbines of different sizes have been evaluated. The sizes of the wind turbines selected correspond to $10 \mathrm{~kW}, 15 \mathrm{~kW}, 20 \mathrm{~kW}$, $25 \mathrm{~kW}$, and $30 \mathrm{~kW}$. The established cost criteria are the following:

- Initial capital of $5000 \mathrm{EUR} / \mathrm{kW}$ for $10 \mathrm{~kW}$ turbines, $4000 \mathrm{EUR} / \mathrm{kW}$ for $30 \mathrm{~kW}$ turbines, and the costs are interpolated for the remaining sizes;

- $\quad$ Replacement cost: it has been defined as $85 \%$ of the initial capital value;

- Operation and Maintenance cost: a value of $45.5 \mathrm{EUR} / \mathrm{kW}$ has been assumed for $10 \mathrm{~kW}$ turbines and a value of $35.6 \mathrm{EUR} / \mathrm{kW}$ for $30 \mathrm{~kW}$ turbines. For the remaining sizes, it was obtained through interpolation. 
In Table 5 the input variables defined to carry out the simulation are shown: the selected turbines, their nominal power, and hub height $(\mathrm{Hh})$ together with the costs determined for the simulation.

Table 5. Wind turbines parameters.

\begin{tabular}{ccccccc}
\hline Wind Turbine & Power (kW) & Hh (m) & $\begin{array}{c}\text { Initial Capital } \\
\text { (EUR) }\end{array}$ & $\begin{array}{c}\text { Replacement } \\
\text { Cost (EUR) }\end{array}$ & $\begin{array}{c}\text { O and M } \\
\text { (EUR/year) }\end{array}$ & $\begin{array}{c}\text { System LCOE } \\
\text { (EUR/kWh) }\end{array}$ \\
\hline Bergey Excel 10 & 10 & 30 & 50,000 & 42,500 & 445.00 & 0.373 \\
Gaia Wind 15 & 15 & 30 & 67,500 & 57,375 & 600.75 & 0.353 \\
Eocycle E20 & 20 & 23 & 80,000 & 68,000 & 712.00 & 0.322 \\
Ecocycle 25 & 25 & 23 & 87,500 & 74,375 & 823.25 & 0.320 \\
PitchWind & 30 & 30 & 90,000 & 76,500 & 801.00 & 0.332 \\
\hline
\end{tabular}

Considering the overall performance of the wind turbines in this application at this site, the wind turbine finally selected from this analysis corresponds to the Eoclycle EO25 Class IIA [47] rated at $25 \mathrm{~kW}$, using a $23 \mathrm{~m}$ hub height, with a LV connection to the system: It is not the highest and it is not the cheapest, but it results in the lowest overall system LCOE.

- Results of the Simulation.

The wind speed data together with the components (and sizes) of the current system and the selected wind turbine, reference values of the components, and the current consumption load of the village were considered as inputs to establish the configuration of the system in the simulation with HOMER PRO. As a remarkable fact, diesel fuel is currently being subsidized by the state of Uruguay; therefore, the cost for the diesel fuel is low $(0.58 € / \mathrm{L})$.

Table 6 shows the result of the simulation of the current system operation (first row) and the optimal result considering a possible incorporation of wind energy in the current system (second row), showing the principal parameters for both cases.

Table 6. Results of the simulation for the alternative, including wind generation, compared to the existing installation.

\begin{tabular}{ccccc}
\hline Case & NPC (\%) & $\begin{array}{c}\text { LCOE } \\
\text { (EUR/kWh) }\end{array}$ & $\begin{array}{c}\text { Fuel Consumption } \\
\text { (L/year) }\end{array}$ & $\begin{array}{c}\text { Renewable } \\
\text { Fraction (\%) }\end{array}$ \\
\hline Existing & $100 \%$ & 0.370 & 33,812 & 27.6 \\
With wind & $94.9 \%$ & 0.320 & 16,717 & 64.2 \\
\hline
\end{tabular}

When comparing both results, the positive impact of the inclusion of a wind generator in the system can be highlighted. The cost of energy fuel consumption is reduced and the renewable fraction exceeds $50 \%$.

- A Sensibility Analysis.

A sensitivity analysis has been carried out to evaluate the impact that changes in the three main affecting parameters may have on the optimal configuration. The following variables have been considered: A variation considering a variation range in the annual average wind speed from 4.5 to $5.5 \mathrm{~m} / \mathrm{s}$ (estimated value was $5.35 \mathrm{~m} / \mathrm{s}$ ); an increase of 5 and $15 \%$ in the village's consumption and a range in the price of fuel from 0.58 (present value) to $0.8 € / \mathrm{L}$. Figure 16 shows the impact of the variability of the wind speed and diesel fuel cost for the existing load consumption.

Figure 16 shows the relationship between the average wind speed at the site and the cost of fuel. The area in green represents the inclusion of wind power, while the black area represents the preservation of the current system. For wind speeds lower than $4.7 \mathrm{~m} / \mathrm{s}$ and fuel costs lower than $0.7 € / \mathrm{L}$, the current system is optimal. Similar graphs can be derived for higher load consumptions, with a slight increase in the dark area as the energy consumption increases. 


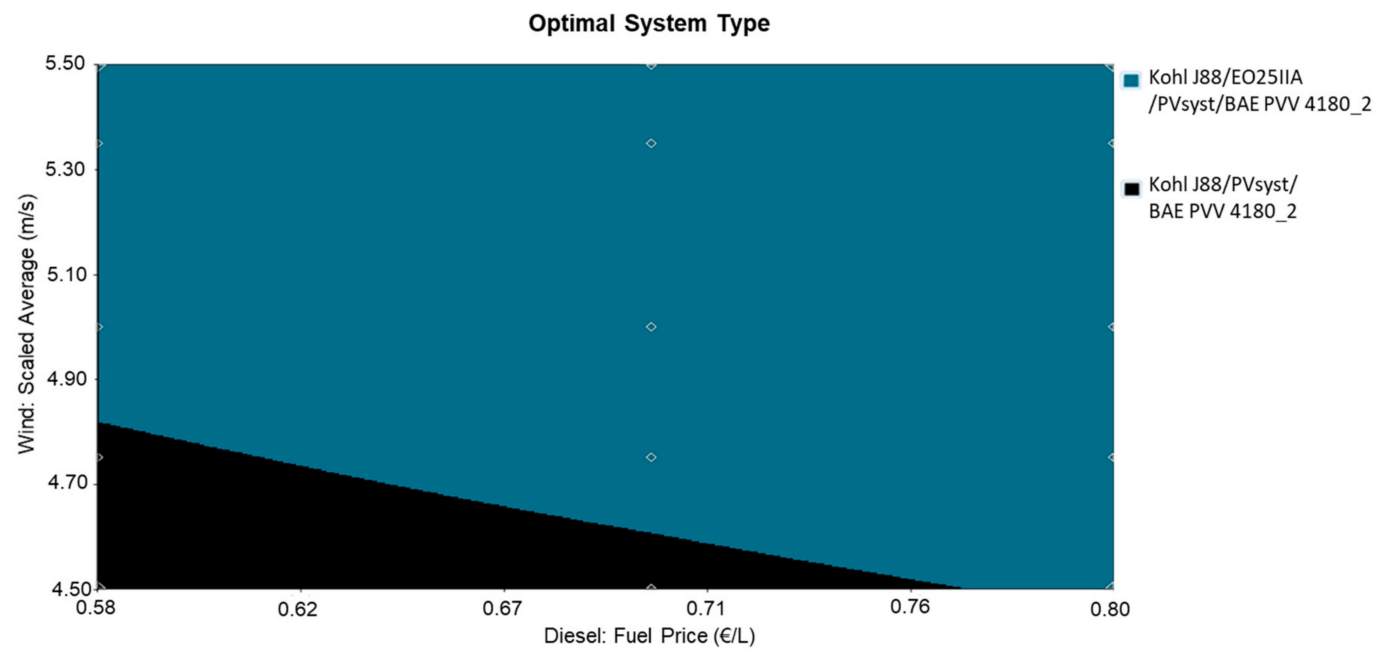

Figure 16. Sensitivity analysis result for diesel fuel cost (0.58-0.8 EUR/1, x axis) and average wind speed (4.5-5.5 m/s, y axis): The black area represents the existing configuration, whereas the blue are represents the configuration including wind generation.

In order to assist in the decision making, it is helpful to perform a long term analysis in order to have an estimation of the variation of wind speed compared to the period used during the analysis. This can be achieved easily using reanalysis data. In Figure 17, a histogram is presented, comparing the annual average wind speed values to the one used for the analysis (corresponding to 2018) for the last 42 years that is downloaded from ERA5 database. From this figure, at least two conclusions can be drawn: one, that the varying range is approximately $\pm 5 \%$ in relation to 2018 (which might be helpful to move in Figure 16); second, that the year used as the reference for the simulation is in the average low area of the distribution and, therefore, it may be considered as relatively conservative (there are 14 years with lower average wind speed and 28 years with similar or higher wind speed).

As a concluding remark, the aim of this analysis is to raise a discussion on the different scenarios and to provide information for decision making.

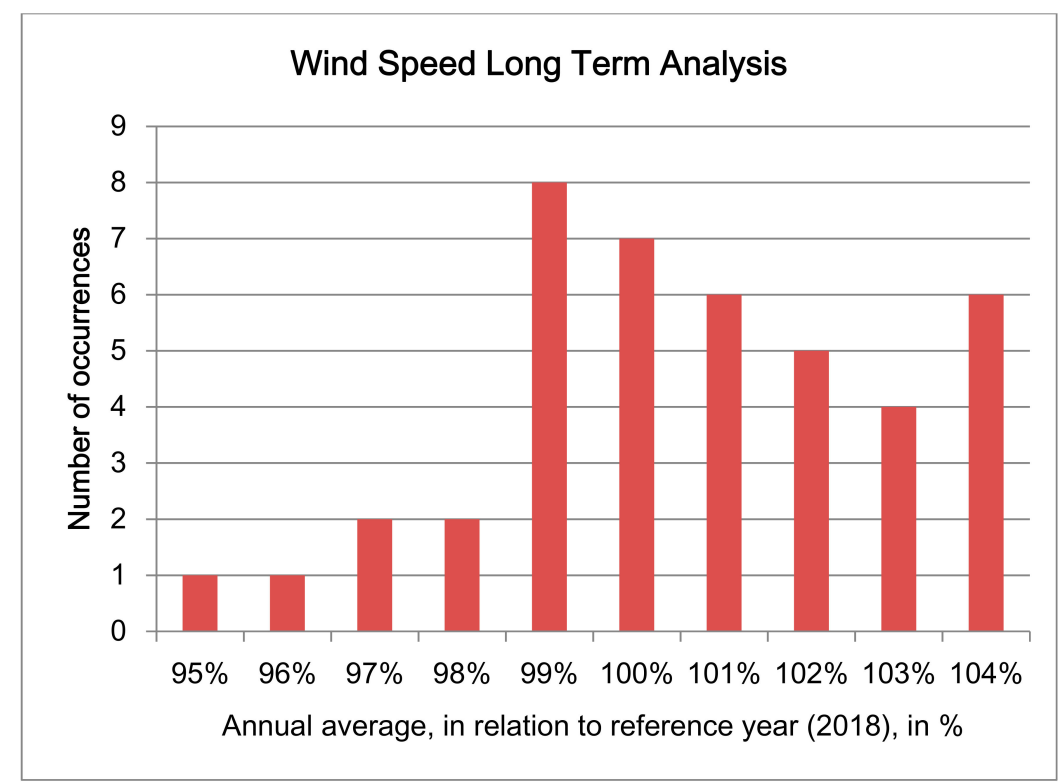

Figure 17. Long term analysis for annual average wind speed using ERA5 42 years' data. 


\section{Discussion}

Having identified some technical barriers that hinders even the consideration of wind generation during the design process of REDPS, a technical methodology to cope with these barriers derived from the inclusion of small wind turbines in hybrid microgrids has been suggested. The target configuration has been established on inverter-based systems, with the possibility to include wind turbines of up to $100 \mathrm{~kW}$ (SWT) based on medium or long term (electrochemical) storage, with optional presence of solar PV generation which are very common nowadays.

With this target in mind, these differences have been focused on the wind resource characterization and on the description of existing technology, i.e., the small wind turbines. In relation to wind resource characterization, due to the need of expressing wind temporal variability (in a hour time frame, at least) and also due to the uncommon existing measuring campaign, a methodology to estimate the wind resource characterization from existing data bases and tools has been introduced. On the other hand, some description has been given for SWT technology in order to assure quality and expected performance of this component. In this manner, the system may be optimized (HOMER Pro software has been proposed for this) and necessary information is prepared in relation to the decision of moving forward with wind installation or rejection based on well-founded analysis and not based on myths relative to SWT.

\section{Conclusions}

This methodology proposed in this publication has been applied to a real case study, an existing PVDPS (installed in 2014) where the possibility of including wind generation is sought. Based on the performance of the existing system and on the characterization of the wind resource and wind technology, the design shows that there is a wide area in the search space of the main parameters (diesel fuel cost, average wind speed, and load consumption) where the installation of a $25 \mathrm{~kW}$ SWT seems recommendable.

Even though the aim of this paper is to present the methodology to permit wind technology consideration during the design process so that it can be implemented anywhere by anyone. In this particular case of application, it is expected that this study may be presented to the governing board of the utility in charge of the system so that they can evaluate the convenience of going forward with the project and to enter into the implementation of the project.

The proposed methodology used commercial software tools with a relatively high cost (mainly for the SWT field). The aim of the authors would be to achieve similar results with free tools but they are not available at the moment. One of the intentions of this paper is also to encourage researchers to keep working on such tools since it has been shown that it can be made.

Author Contributions: Conceptualization, L.A., N.B. and A.B.; methodology, L.A.; software, N.B. and L.A.; validation, N.B.; formal analysis, L.A. and N.B.; investigation, N.B.; resources, A.B.; data curation, N.B.; writing—original draft preparation, L.A. and N.B.; writing-review and editing, L.A., N.B. and A.B.; visualization, A.B.; supervision, L.A.; project administration, A.B. All authors have read and agreed to the published version of the manuscript.

Funding: This research received no external funding.

Institutional Review Board Statement: Not applicable.

Informed Consent Statement: Not applicable.

Data Availability Statement: The data presented in this study might be available on request from the UTE author. The data are not publicly available due to confidentiality issues.

Acknowledgments: The authors would like to thank UL for their support with information and to myWindTurbine.com (a dedicated tool for the planning of small domestic turbines, which was created as a joint effort between DTU Wind Energy and EMD International A/S.) for some free licenses. 
Conflicts of Interest: The authors declare no conflict of interest. The support from the software companies had no role in the design of the study; in the collection, analyses, or the interpretation of data; in the writing of the manuscript or in the decision to publish the results.

\section{Appendix A. Pictures from the System under Study}

In this Appendix A, some pictures from the site and from the particular components of the existing system are shown.
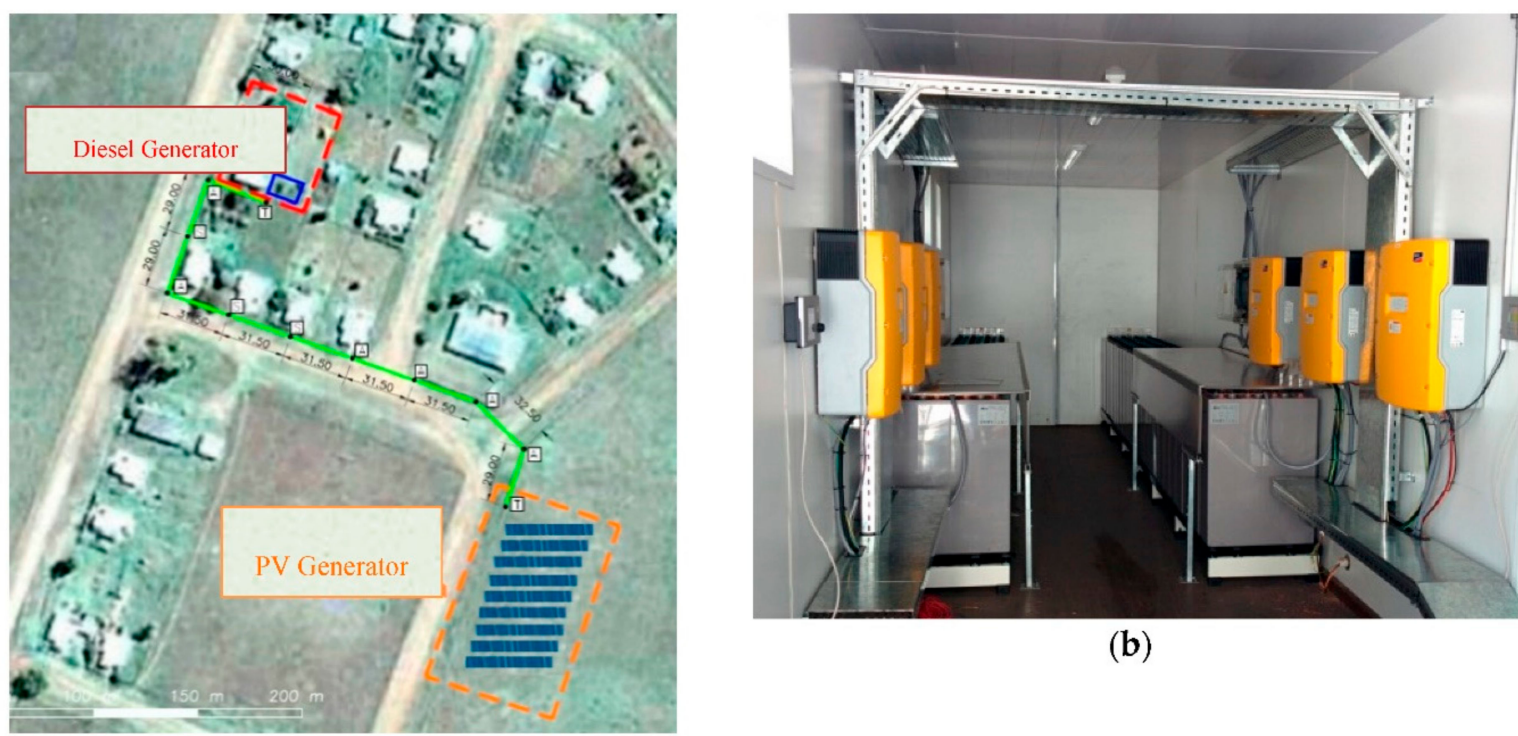

(b)

(a)

Figure A1. (a) Aerial view of the site, with the indication of the existing solar PV array and the gensets building; (b) The two battery banks and the six Sunny Island power converters.

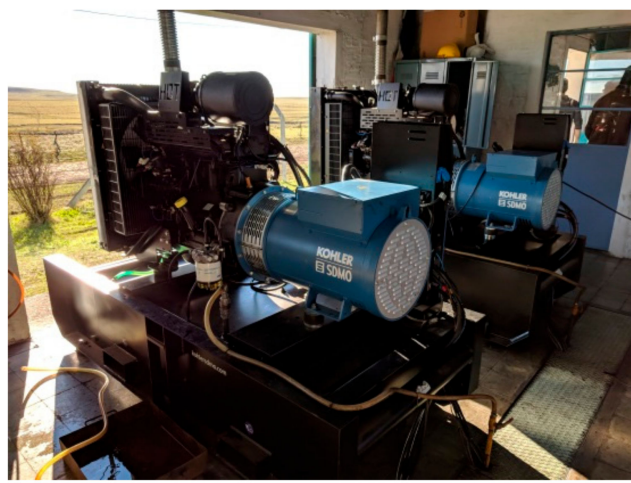

(a)

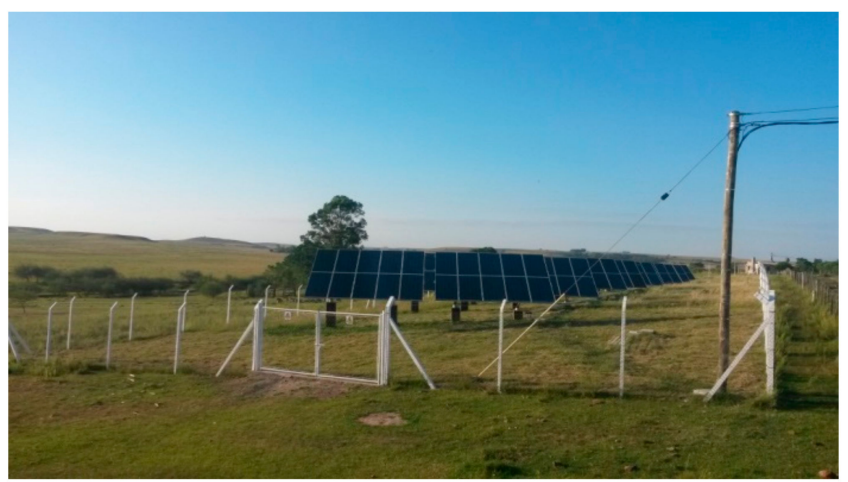

(b)

Figure A2. (a) The inside of the gensets building with the two diesel generators; (b) A general view of the solar PV generator.

\section{References}

1. Baring-Gould, E.I.; Dabo, M. Technology, performance, and market report of wind-diesel applications for remote and island communities. In Proceedings of the European Wind Energy Conference, Marseille, France, 16-19 March 2009.

2. Mazzeo, D.; Matera, N.; De Luca, P.; Baglivo, C.; Congedo, P.M.; Oliveti, G. A literature review and statistical analysis of photovoltaic-wind hybrid renewable system research by considering the most relevant 550 articles: An upgradable matrix literature database. J. Clean. Prod. 2021, 126070. [CrossRef]

3. Lian, J.; Zhang, Y.; Ma, C.; Yang, Y.; Chaima, E. A review on recent sizing methodologies of hybrid renewable energy systems. Energy Convers. Manag. 2019, 199, 112027. [CrossRef] 
4. Bloomberg and SEforALL, 2020. State of the Global Mini-grids Market Report 2020. Available online: https://www.seforall.org/ system/files/2020-06/MGP-2020-SEforALL.pdf (accessed on 3 July 2021).

5. Empresa de Pesquisa Energética (EPE). Planejamento do Atendimento dos Sistemas Isolados; Empresa de Pesquisa Energética: Brasília, Brazil, 2014. (In Portuguese)

6. ESMAP. Mini Grids for Half a Billion People: Market Outlook and Handbook for Decision Makers; World Bank: Washington, DC, USA, 2019.

7. Johannsen, R.M.; Østergaard, P.A.; Hanlin, R. Hybrid photovoltaic and wind mini-grids in Kenya: Techno-economic assessment and barriers to diffusion. Energy Sustain. Dev. 2020, 54, 111-126. [CrossRef]

8. Micangeli, A.; Del Citto, R.; Kiva, N.; Santori, G.; Gambino, V.; Kiplagat, J.; Viganò, D.; Fioriti, D.; Poli, D. Energy Production Analysis and Optimization of Mini-Grid in Remote Areas: The Case Study of Habaswein, Kenya. Energies 2017, $10,2041$. [CrossRef]

9. Lopes, L.; Mauch, K.; Katiraie, F.; Arribas. L. PV Hybrid Mini-Grids: Applicable Control Methods for Various Situations; Report IEA-PVPS T11-07:2012. 2012. Available online: https:/ /iea-pvps.org/wp-content/uploads/2020/01/rep11_07.pdf (accessed on 27 September 2020).

10. International Electrotechnical Commission IEC 61724. Photovoltaic System Performance Monitoring-Guidelines for Measurement, Data Exchange and Analysis; Edition 1.0; International Electrotechnical Commission: Geneva, Switzerland, 1998.

11. Hunter, R.; Elliot, G. Wind-Diesel Systems-A Guide to the Technology and its Implementation; Cambridge University Press: Cambridge, UK, 1994. [CrossRef]

12. International Electrotechnical Commission IEC 62257-3. Recommendations for Small Renewable Energy and Hybrid Systems for Rural Electrification-Part 3: Project Development and Management; Draft Technical Specification Edition 1; International Electrotechnical Commission: Geneva, Switzerland, 2004.

13. Baring-Gould, I. Successful Project Development. In Proceedings of the Wind-Diesel Workshop, Ottawa, ON, Canada, 1-2 June 2009.

14. Clausen, N.E.; Bindner, H.; Frandsen, S.; Hansen, J.C.; Hansen, L.H.; Lundsager, P. Isolated Systems with Wind Power An Implementation Guideline; Risoe National Laboratory: Roskilde, Denmark, 2001.

15. Small Wind Guidebook. Available online: https://windexchange.energy.gov/small-wind-guidebook (accessed on 27 September 2020).

16. Bechmann, A.; Conti, D.; Davis, N.; Hansen, B.O.; Kelly, M.C.; Mortensen, N.G.; Nielsen, M.; Badger, J.; Pena Diaz, A. MyWindTurbine -Energy Yield Calculations; DTU Wind Energy: Roskilde, Denmark, 2016.

17. IEA Wind. Task 27 Micro-Siting Small Wind Turbines for Highly Turbulent Sites; Expert Group Report on Recommended Practices, International Energy Agency: Paris, France, 2018.

18. Brower, M.C.; Barton, M.S.; Lledó, L.; Dubois, J. Study of Wind Speed Variability Using Global Reanalysis Data. 2013. Available online: https: / / aws-dewi.ul.com/assets / A-Study-of-Wind-Speed-Variability-Using-Global-Reanalysis-Data1.pdf (accessed on 3 July 2021).

19. Renewables Ninja Web Tool. Available online: www.renewables.ninja (accessed on 3 July 2021).

20. ECMWF-Climate Reanalysis Web Page. Available online: https://www.ecmwf.int/en/research/climate-reanalysis (accessed on 30 September 2020).

21. WAsP Homepage. Available online: https://www.wasp.dk/ (accessed on 29 September 2020).

22. Weather Research and Forecasting Model. WRF Homepage. Available online: https://www.mmm.ucar.edu/weather-researchand-forecasting-model (accessed on 3 July 2021).

23. EMD International. EMD-WRF Global On-demand Mesoscale Services ERA5, ERA-Interim, MERRA2 and CFSR. Technical note. 2017. Available online: http://help.emd.dk/knowledgebase/content/TechNotes/TechNote_6_EMD-WRF_On-Demand.pdf (accessed on 3 July 2021).

24. Cruz, I.; Arribas, L. Small Wind Turbines. In Wind Energy THE FACTS; Routledge: London, UK, 2009.

25. IRENA. Quality Infrastructure for Renewable Energy Technologies Small Wind Turbines. 2015. Available online: https:/ /irena. org/-/media/Files/IRENA/Agency/Publication/2015/IRENA_QI_2_SWTs_2015.pdf (accessed on 3 July 2021).

26. World Wind Energy Association. Quality Web Page. Available online: https://smallwind.wwindea.org/quality/ (accessed on 29 September 2020).

27. Arribas, L.; Barquero, C.; Cruz, I.; Avia, F. The Small Wind Turbines Market in Spain. Available online: http:/ /www.ciemat.es / portal.do?TR=A\&IDR=1\&identificador=852 (accessed on 3 July 2021). (In Spanish)

28. myWindTurbine Homepage. Available online: https://www.mywindturbine.com/ (accessed on 29 September 2020).

29. HOMER Energy. HOMER (Hybrid Optimization of Multiple Energy Resources) Homepage. Available online: https://www. homerenergy.com (accessed on 29 September 2020).

30. Folkecenter; 2016 Small Wind Catalogue. Available online: http:// folkecenter.eu/pages/Small-wind-turbine-catalogue.html (accessed on 3 July 2021).

31. Orrell, A.C.; Rhoads-Weaver, H.E.; Flowers, L.T.; Jenkins, J.O.; Gagne, M.N.; Sahl, K.M.; Pro, B.H.; Baranowski, R.E. 2012 Market Report on U.S. Wind Technologies in Distributed Applications. Available online: https://www.pnnl.gov/main/publications/ external/technical_reports/PNNL-22537.pdf (accessed on 30 September 2020). 
32. Woofenden, I. 2014 Wind Turbine Buyer's Guide. In Home Power Magazine 161; Oregon, USA, 2014. Available online: https: //www.scribd.com/document/481612016/hp-161-pdf (accessed on 30 September 2020).

33. Sigrin, B.; Gleason, M.; Preus, R.; Baring-Gould, I.; Margolis, R. Distributed Generation Market Demand Model (dGen): Documentation; NREL/TP-6A20-65231; National Renewable Energy Laboratory: Golden, CO, USA, 2016.

34. Zimmermann, J. Case study for CORAL BAY Energy modelling for a WIND DIESEL and stabilization hybrid system. In Proceedings of the Microgrid Deployment Workshop Fall, Barcelona, Spain, 20 September 2014.

35. Arribas, L.; Bopp, G.; Lippkau, A.; Mauch, K. World-Wide Overview of Design and Simulation Tools for Hybrid PV Systems. Report IEA-PVPS T11-01:2011. 2011. Available online: https://iea-pvps.org/wp-content/uploads/2020/01/rep11_01.pdf (accessed on 27 September 2020).

36. The World Bank. Designing Sustainable Off-Grid Rural Electrification Projects: Principles and Practices; The World Bank: Washington, DC, USA, 2008.

37. Jacquin, P.; Ortiz, B.; Vallvé, X. Social, Economic and Organizational Framework for Sustainable Operation of PV Hybrid Systems within Mini-Grids. IEA PVPS Task 11, Report IEA-PVPS T11-05:2011. 2011. Available online: https://iea-pvps.org/wp-content/ uploads/2020/01/rep11_05.pdf (accessed on 27 September 2020).

38. UNDP. Wind Diesel Generation Systems for 10 Islands in the Chiloe Archipelago. UNDP International call for Proposals 023/2007. 2007. Available online: http:/ / procurement-notices.undp.org/view_notice.cfm?notice_id=1193 (accessed on 3 July 2021). (In Spanish)

39. MEASNET. Evaluation of Site-Specific Wind Conditions. MEASNET Procedure. Version 2. April 2016. Available online: https://www.measnet.com/wp-content/uploads/2016/05/Measnet_SiteAssessment_V2.0.pdf (accessed on 3 July 2021).

40. Olsen, T.; Preus, R. Small Wind Site Assessment Guidelines. Technical Report NREL/ TP-5000-63696. September 2015. Available online: https: / / www.nrel.gov/docs/fy15osti/63696.pdf (accessed on 3 July 2021).

41. Global Wind Atlas Homepage. Available online: https://globalwindatlas.info/ (accessed on 29 September 2020).

42. POWER Project Homepage. Available online: https:/ / power.larc.nasa.gov/ (accessed on 29 September 2020).

43. Wind Navigator Homepage. Available online: https://aws-dewi.ul.com/software/windographer/windnavigator/ (accessed on 29 September 2020).

44. Arribas, L.; Cano, L.; Cruz, I.; Mata, M.; Llobet, E. PV-wind hybrid system performance: A new approach and a case study. Renew. Energy 2010, 35, 128-137. [CrossRef]

45. Shuttle Radar Topography Mission. WindPro Knowledgebase. Available online: https://help.emd.dk/mediawiki/index.php? title=Shuttle_Radar_Topography_Mission (accessed on 23 June 2021).

46. Global Land Cover Characteristics. WindPro Knowledgebase. Available online: https://help.emd.dk/mediawiki/index.php? title=Global_Land_Cover_Characteristics (accessed on 23 June 2021).

47. Eoclycle. EO25 Class IIA Wind Turbine. Specification Sheet. 2020. Available online: http://energieclub.weebly.com/uploads/1/ 1/6/7/11670442/ eocycle-data-sheet-eo2512-may13.pdf (accessed on 30 September 2020). 